Prepared for the U.S. Department of Energy under Contract DE-AC05-76RL01830

\title{
ANALYSIS OF RICIN TOXIN PREPARATIONS FOR CARBOHYDRATE AND FATTY ACID ABUNDANCE AND ISOTOPE RATIO INFORMATION
}

DS Wunschel, PhD

$\mathrm{H}$ Kreuzer, PhD

K Antolick

HA Colburn, PhD

J Moran, PhD

A Melville

December 2009

Pacific Northwest

NATIONAL LABORATORY

Proudly Operated by Battelle Since 1965 


\title{
DISCLAIMER
}

This report was prepared as an account of work sponsored by an agency of the United States Government. Neither the United States Government nor any agency thereof, nor Battelle Memorial Institute, nor any of their employees, makes any warranty, express or implied, or assumes any legal liability or responsibility for the accuracy, completeness, or usefulness of any information, apparatus, product, or process disclosed, or represents that its use would not infringe privately owned rights. Reference herein to any specific commercial product, process, or service by trade name, trademark, manufacturer, or otherwise does not necessarily constitute or imply its endorsement, recommendation, or favoring by the United States Government or any agency thereof, or Battelle Memorial Institute. The views and opinions of authors expressed herein do not necessarily state or reflect those of the United States Government or any agency thereof.

\author{
PACIFIC NORTHWEST NATIONAL LABORATORY \\ operated by \\ BATTELLE \\ for the \\ UNITED STATES DEPARTMENT OF ENERGY \\ under Contract DE-AC05-76RL01830
}

Printed in the United States of America

Available to DOE and DOE contractors from the

Office of Scientific and Technical Information,

P.O. Box 62, Oak Ridge, TN 37831-0062;

ph: (865) 576-8401

fax: $(865) 576-5728$

email: reports@adonis.osti.gov

\footnotetext{
Available to the public from the National Technical Information Service, U.S. Department of Commerce, 5285 Port Royal Rd., Springfield, VA 22161 ph: (800) 553-6847 fax: $(703) 605-6900$

email: orders@ntis.fedworld.gov

online ordering: http://www.ntis.gov/ordering.htm
}

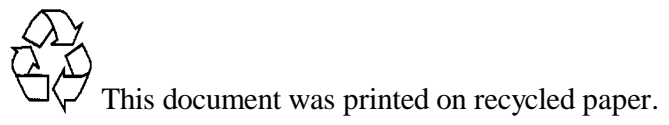




\title{
ANALYSIS OF RICIN TOXIN PREPARATIONS FOR CARBOHYDRATE AND FATTY ACID ABUNDANCE AND ISOTOPE RATIO INFORMATION
}

\author{
DS Wunschel, PhD HA Colburn, PhD \\ $\mathrm{H}$ Kreuzer, $\mathrm{PhD} \quad J$ Moran, $\mathrm{PhD}$ \\ K Antolick A Melville
}

December 2009

Prepared for the U.S. Department of Energy

under Contract DE-AC05-76RL01830

Pacific Northwest National Laboratory

Richland, Washington 99352 


\subsection{Executive Summary}

This report describes method development and preliminary evaluation for analyzing castor samples for signatures of purifying ricin. Ricin purification from the source castor seeds is essentially a problem of protein purification using common biochemical methods. Indications of protein purification will likely manifest themselves as removal of the non-protein fractions of the seed. Two major, non-protein, types of biochemical constituents in the seed are the castor oil and various carbohydrates. The oil comprises roughly half the seed weight while the carbohydrate component comprises roughly half of the remaining "mash” left after oil and hull removal.

Different castor oil and carbohydrate components can serve as indicators of specific toxin processing steps. Ricinoleic acid is a relatively unique fatty acid in nature and is the most abundant component of castor oil. The loss of ricinoleic acid indicates a step to remove oil from the seeds. The relative amounts of carbohydrates and carbohydrate-like compounds, including arabinose, xylose, myo-inositol fucose, rhamnose, glucosamine and mannose detected in the sample can also indicate specific processing steps. For instance, the differential loss of arabinose relative to mannose and $\mathrm{N}$-acetyl glucosamine indicates enrichment for the protein fraction of the seed using protein precipitation.

The methods developed in this project center on fatty acid and carbohydrate extraction from castor samples followed by derivatization to permit analysis by gas chromatography-mass spectrometry (GC-MS). Method descriptions herein include: the source and preparation of castor materials used for method evaluation, the equipment and description of procedure required for chemical derivatization, and the instrument parameters used in the analysis. Two types of derivatization methods describe analysis of carbohydrates and one procedure for analysis of fatty acids. Two types of GC-MS analysis is included in the method development, one employing a quadrupole MS system for compound identification and an isotope ratio MS for measuring the stable isotope ratios of deuterium and hydrogen $(\mathrm{D} / \mathrm{H})$ in fatty acids. Finally, the method for analyzing the compound abundance data is included.

This study indicates that removal of ricinoleic acid is a conserved consequence of each processing step we tested. Furthermore, the stable isotope D/H ratio of ricinoleic acid distinguished between two of the three castor seed sources. Concentrations of arabinose, xylose, mannose, glucosamine and myo-inositol differentiated between crude or acetone extracted samples and samples produced by protein precipitation. Taken together these data illustrate the ability to distinguish between processes used to purify a ricin sample as well as potentially the source seeds. 


\subsection{Table of Contents}

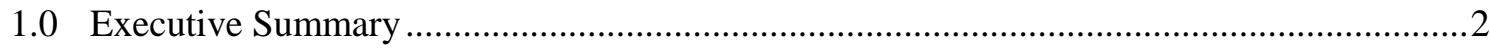

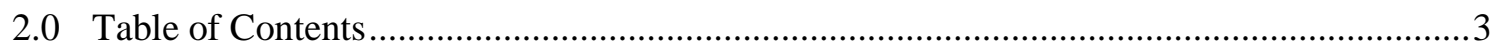

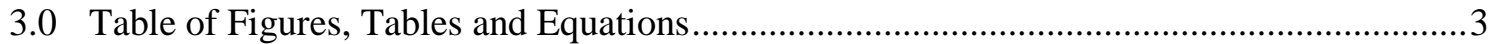

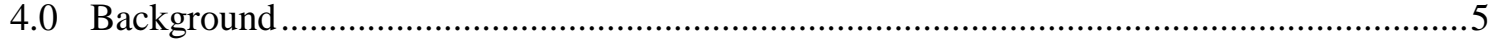

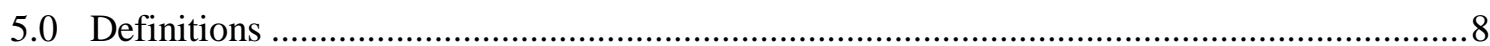

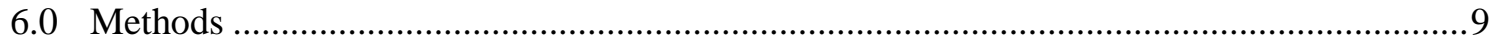

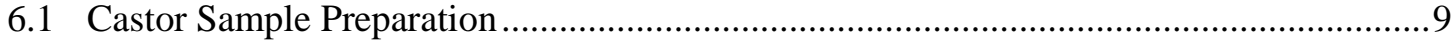

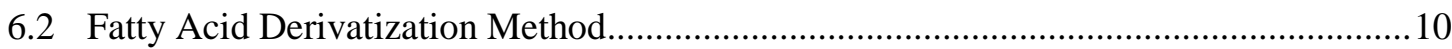

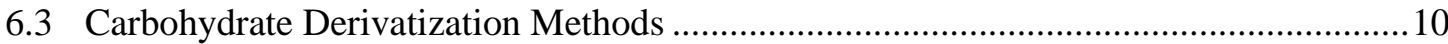

6.4 Gas Chromatography Mass Spectrometry Data Acquisition............................................13

6.5 Isotope Ratio Mass Spectrometry Analysis of Methyl Ricinoleate..................................14

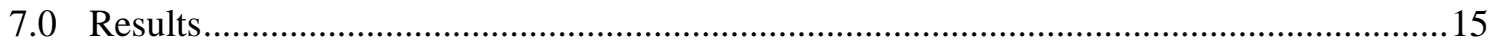

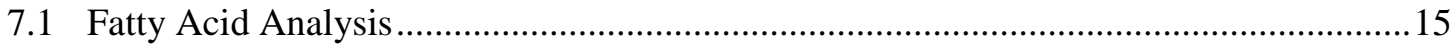

1. Gas Chromatography Flame Ionization Detection (GC-FID) …...........................15

2. Gas Chromatography Mass Spectrometry (GC-MS) ….......................................15

3. Gas Chromatography Isotope Ratio Mass Spectrometry (GC-IRMS) ...................19

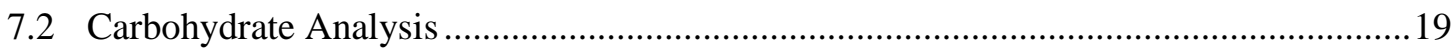

1. Alditol Acetate Derivative Marker Abundance......................................................19

2. Trimethylsilyl Carbohydrate Derivative Analysis....................................................24

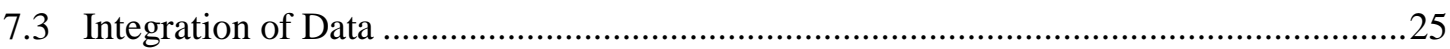

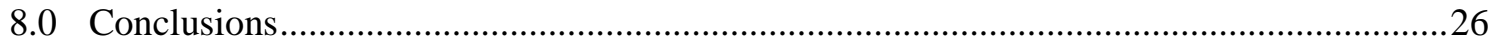

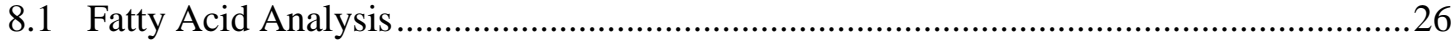

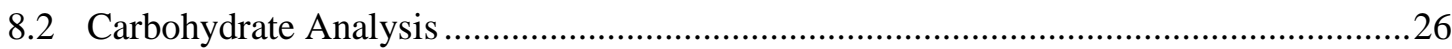

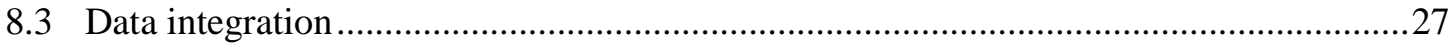

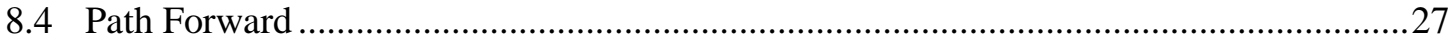

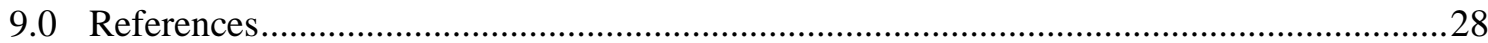

10.0 Appendix A PNNL Castor Bean Preparation Methods ....................................................29

11.0 Appendix B Title: Preparation and Analysis of Fatty Acid Methyl Ester Derivatives from

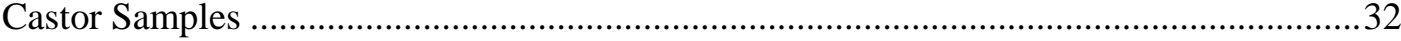

12.0 Appendix C Title: Preparation and Analysis of Alditol Acetate Carbohydrate Derivatives

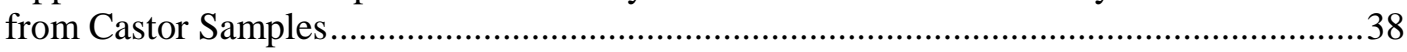

13.0 Appendix D Title: Preparation and Analysis of Trimethylsilyl Carbohydrate Derivatives from Castor Samples. .48

\subsection{Table of Figures, Tables and Equations}

Figure 1 Diagram of basic ricin processing steps. 


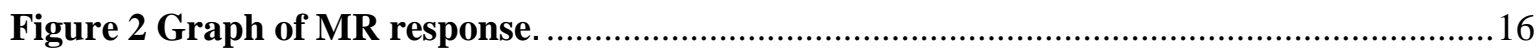

Figure 3. Chromatogram of FAME prepared from crude mash sample. ............................17

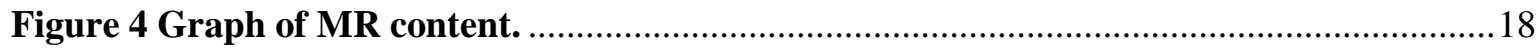

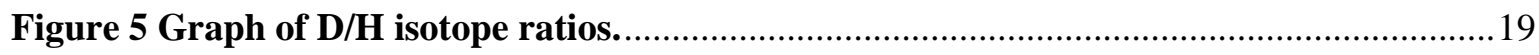

Figure 6. Bar graph comparing first two preparation types.................................................21

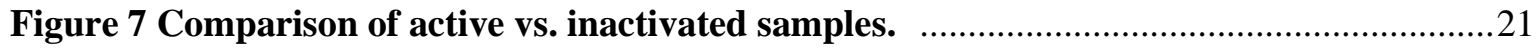

Figure 8. Graph comparing castor samples prepared at different times...............................22

Figure 9 Comparison of four toxin preparations applied to three sources of castor seeds......24

Figure 10. Principal component scores plot for the four toxin preparation types...................25

Table 1 Five example ricin purification recipes with the basic steps for purification listed......6

Table 2 Monosaccharide standards used............................................................................11

Table 3 Standard monosaccharides used for TMS derivatization. ......................................12

Table 4 average \% weight and standard deviation of methyl ricinoleate...............................18

Table 5 Comparison of carbohydrate content from active and inactive sample. ..................20

Table 6. Table comparing castor samples prepared at distinct times. ..................................22

Table 7 Comparison of carbohydrate average \% sample weight for three sources of castor

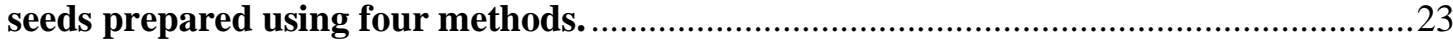

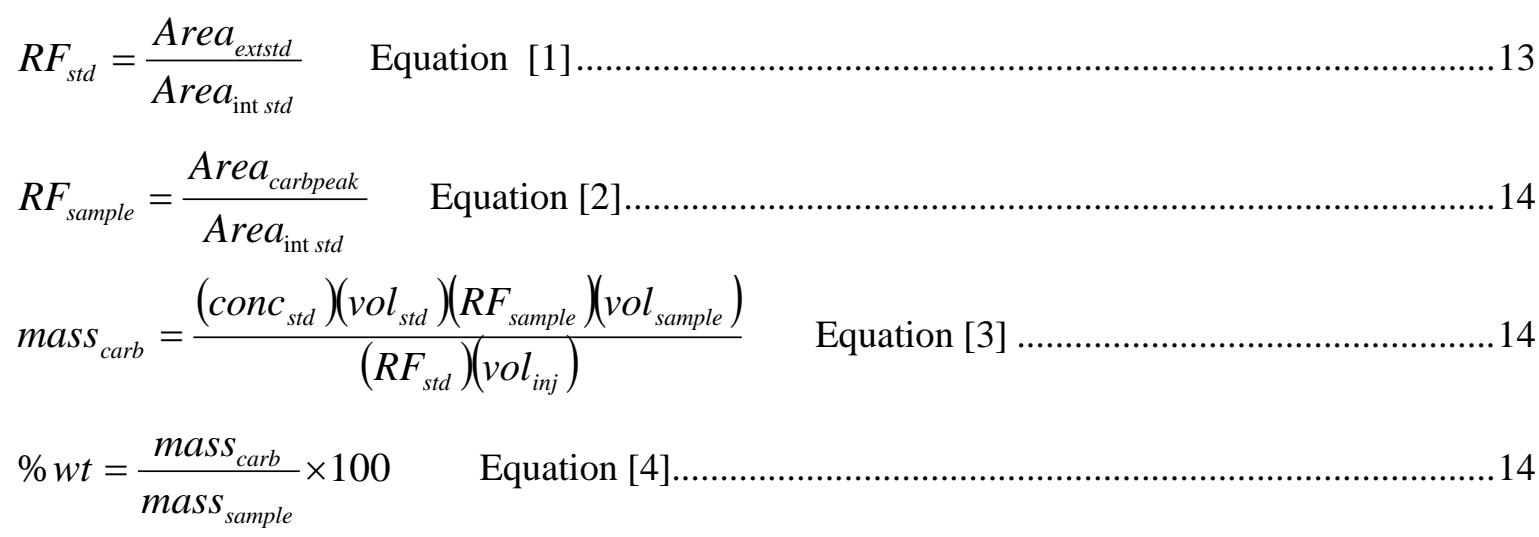




\subsection{Background}

This project focuses on forensic analysis of plant toxins, in particular ricin, which is derived from castor seeds ( $R$. communis). Techniques presented here are also applicable to other types of toxins. Ricin is isolated from the castor seed produced by Ricinis communis. Ricin is a $66 \mathrm{kDa}$ plant lectin composed of 2 chains, the A-chain and B-chain, linked by a disulfide bond ${ }^{1}$. The B-chain is a $32 \mathrm{kDa}$ lectin subunit of ricin which binds galactose residues on the surface of a variety of cell types. Its role is to aid in internalization of the catalytic A chain. The A-chain is a $34 \mathrm{kDa}$ catalytic subunit which contains N-glycosidase activity which cleaves A4324 of the $28 \mathrm{~S}$ ribosome thereby inhibiting cellular protein synthesis ${ }^{2}$. The complete toxin has a lethal dose of $\sim 1-3 \mu \mathrm{g} /$ $\mathrm{kg}$ body weight. The "select agent" level is possession of $100 \mathrm{mg}$ or more of this toxin ${ }^{3}$. Toxicity of the individual subunits are $>1,000$ fold less toxic than the holotoxin ${ }^{4}$.

Previous reports focused on the potential threat of ricin and associated methods for ricin purification $^{1,5}$. DNA profiles obtained from preparations of ricin and other toxins can reveal the genetic variety of the source material, but will be of little to no forensic utility for differentiating processing methods. Techniques for differentiating among toxin preparations from genetically identical source materials or widespread cultivars are needed. The methods for extracting ricin from castor seeds are generally variations on common themes for biochemical purification of proteins from a complex sample matrix ${ }^{5}$.

Castor beans are $40-60 \%$ oil by weight ${ }^{6}$ and castor oil is an abundant commodity used by the petroleum industry. The top castor producing countries are India, China and Brazil ${ }^{7}$. However the castor plant grows wild in tropical and sub-tropical climates and is widely available as an ornamental. The ubiquity of castor beans makes the source materials for purifying ricin difficult to control. Furthermore, numerous methods by which ricin can be purified are available in various booklets, pamphlets and internet sites such as "TOTSE How to Make Ricin”, “The Poor Man's James Bond,” “Assorted Nasties”, "Silent Death", and a laboratory recipe for ricin preparation ${ }^{8-13}$. Examples of these recipes are provided in Table 1. It should be noted that not all recipes yield pure preparations or have been conclusively demonstrated to be effective.

\begin{tabular}{|c|c|c|c|c|c|}
\hline $\begin{array}{c}\text { Method } \\
\text { Description } \\
\text { and Source }\end{array}$ & $\begin{array}{c}\text { Castor } \\
\text { seed mash }\end{array}$ & $\begin{array}{c}\text { Solvent } \\
\text { Extraction/Drying } \\
12\end{array}$ & $\begin{array}{c}\text { Acid extraction } \\
\text { /Sodium Sulfate } \\
\text { Protein } \\
\text { Precipitation }\end{array}$ & $\begin{array}{c}\text { Epsom Salt } \\
\text { Protein } \\
\text { Precipitation }\end{array}$ & $\begin{array}{c}\text { Affinity } \\
\text { purification } \\
10\end{array}$ \\
\hline
\end{tabular}




\begin{tabular}{|c|c|c|c|c|c|}
\hline Procedure & $\begin{array}{l}\text { 1) Grind } \\
\text { beans with } \\
\text { or without } \\
\text { peeling }\end{array}$ & $\begin{array}{l}\text { 1) Soak beans in } \\
\text { lye. } \\
\text { 2) Peel \& grind in } \\
\text { coffee grinder or } \\
\text { blender with } \\
\text { acetone or other } \\
\text { solvent. } \\
\text { 3) Let stand } 3 \text { days } \\
\text { 4) pour through } \\
\text { coffee filter, dry \& } \\
\text { collect. }\end{array}$ & $\begin{array}{l}\text { 1) Peel \& grind } \\
\text { beans } \\
\text { 2) Slurry pressed } \\
\text { bean pumice with } \\
\text { acidic water } \\
\text { 3) Filter \& } \\
\text { neutralize with } \\
\mathrm{Na}_{2} \mathrm{CO}_{3} \\
\text { 4) Precipitate } \\
\text { filtrate with } \mathrm{Na}_{2} \mathrm{SO}_{4} \\
\text { 5) Slurry in } \mathrm{CCl}_{4} \\
\text { and skim off ricin } \\
\text { 6) Dry \& grind. }\end{array}$ & $\begin{array}{l}\text { 1) Soak beans in } \\
\text { lye } \\
\text { 2) Peel \& crush } \\
\text { 3) Squeeze out oil } \\
\text { in paper towels. } \\
\text { 4) Slurry in salt } \\
\text { water } \\
\text { 5) Strain through } \\
\text { coffee filter } \\
\text { 6) Precipitate with } \\
\text { MgSO } \\
\text { 7) Collect on filter, } \\
\text { dry and scrape off }\end{array}$ & $\begin{array}{l}\text { 1) Blend seeds } \\
\text { in salt water } \\
\text { 2) Refrigerate } \\
\text { 24 hrs } \\
\text { 3) Strain } \\
\text { solution } \\
\text { through } \\
\text { cheesecloth } \\
\text { 4) Precipitate } \\
\text { with } \mathrm{NH}_{4} \mathrm{SO}_{4} \\
\text { 5) Affinity } \\
\text { purification on } \\
\text { sepharose or } \\
\text { lectin column }\end{array}$ \\
\hline
\end{tabular}

Table 1 Five example ricin purification recipes with the basic steps for purification listed.

Most preparation procedures begin by removal of the bean coat to access the underlying mash and oil. Secondarily, oil can be extracted by solvent wash or blotting. Further steps can be taken to solubilize the toxin from the starch-rich mash and precipitation of the glycoproteins. Finally, an affinity purification step can be used to purify ricin from other proteins and toxic lectins. A schematic of general steps for purification of ricin from castor seeds is given in Figure 1. The specific recipes for toxin preparation are provided in appendix A. A critical outcome of this work is to determine the specific fatty acid and carbohydrate profiles that provide information on whether and how a castor sample has been processed to purify the toxin ricin.

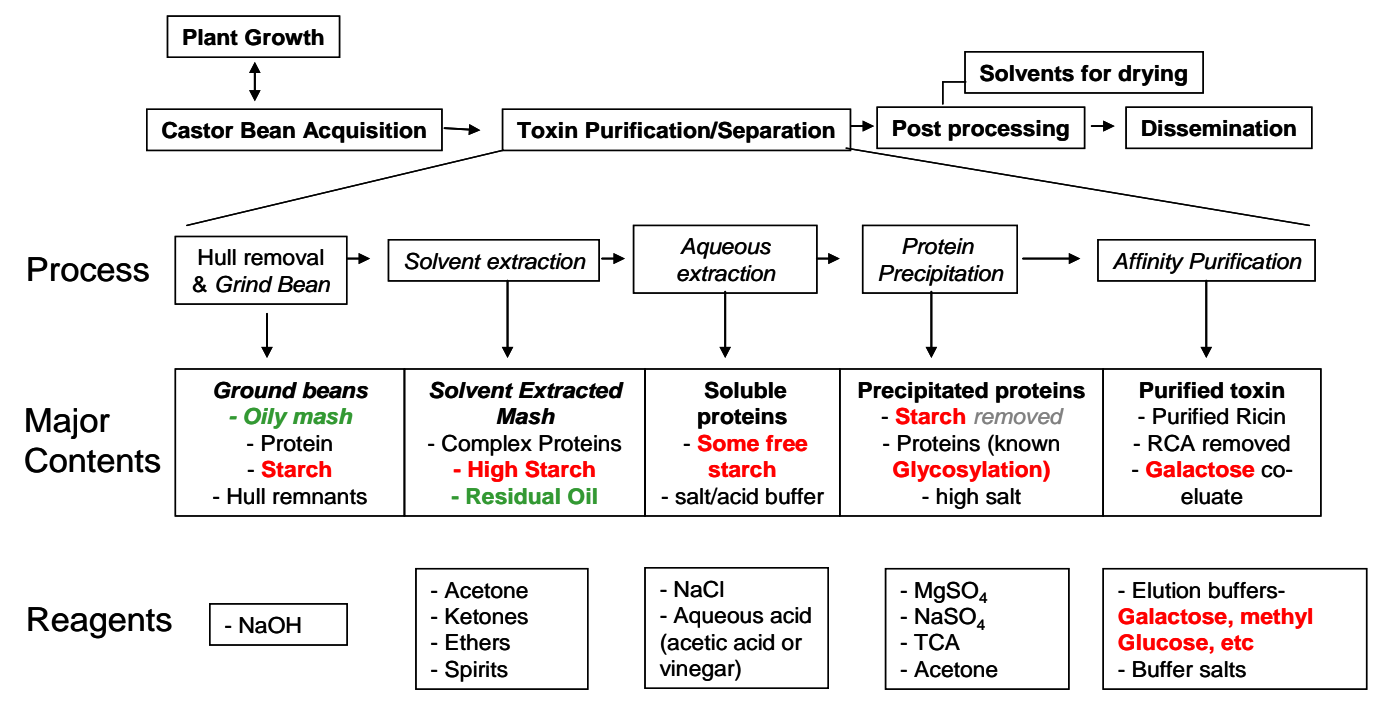

Carbohydrate markers in red; Fatty Acid markers in green

Figure 1 Diagram of basic ricin processing steps. The Purification/Separation portion of the process has been expanded to examine the basic steps performed in varying recipes. 
Toxin extraction steps are likely to differentially remove fatty acids and carbohydrates. For example, castor beans contain the distinctive fatty acid ricinoleic acid. Ricinoleic acid (RA) is an unusual hydroxylated and unsaturated fatty acid that is the major constituent ( $89 \%$ ) of castor oil ${ }^{7,14}$. Following derivatization to the fatty acid methyl ester (FAME) form, RA can be separated from other fatty acids by gas chromatography (GC) and identified by mass spectrometry (MS). The majority of carbohydrate constituents remaining after oil removal include starch, cell wall polymers (cellulose and hemicellulose), galactose-inositols present for desiccation resistance and protein glycosylation. Components of these plant structures include myo and chiro-inositol derived from galactinol ${ }^{15}$, arabinose and xylose in cell wall hemicellulose ${ }^{16}$, mannose and $\mathrm{N}$-acetyl glucosamine in protein glycosylation ${ }^{17}$. Affinity purification is likely to use galactose or other monosaccharides as a reagent for elution leading to an abundance of specific monosaccharides in these samples. Variation in the abundance of these compounds can potentially provide differentiating information between acetone extracted mash and protein precipitated samples. Analysis of carbohydrates follows their hydrolysis to monomers and derivatization to either alditol acetate or trimethyl silyl forms. The relative abundance of each carbohydrate is measured as alditol acetate in this work based on previously applied methods ${ }^{18,19}$.

In addition to concentration data, further information can be obtained from the stable isotope ratio of seed constituents. This has been demonstrated through past stable isotope investigation of a broad range of castor seeds and purified toxins ${ }^{20}$. Independent of castor variety, individual samples from different growth regions could be differentiated by their deuterium to hydrogen $(\mathrm{D} / \mathrm{H})$ and ${ }^{18} \mathrm{O} /{ }^{16} \mathrm{O}$ for those compounds. That work examined whole seeds, castor oil and purified toxin from several seed varieties as well as differing geographic location of plant cultivation. In this project we build on that concept by applying a stable isotope ratio analysis to specific castor compound. The $\mathrm{D} / \mathrm{H}$ isotope ratios of derivatized RA will be the primary target. We also investigated alternative derivatization methods for carbohydrate analysis to permit their ${ }^{18} \mathrm{O} /{ }^{16} \mathrm{O}$ isotope ratio measurements on those markers as well.

Consideration must be made for the affect of both toxin sample processing and derivatization of samples on the isotopic content of a given compound. Derivatized fatty acids have a relatively small number of hydrogen atoms added to them when converted to methyl ester form. None of the $\mathrm{H}$ atoms are exchangeable during the saponification and esterification steps. However, introduction of additional oxygen atoms on to a carbohydrate can occur during preparation for analysis. Acid hydrolysis of a carbohydrate polymer will add $\mathrm{H}_{2} \mathrm{O}$ across the bonds linking monomers and bond $\mathrm{O}$ atoms from water to the monomer. Likewise derivatization adds $\mathrm{O}$ atoms to the compound, potentially altering the measured ${ }^{18} \mathrm{O} /{ }^{16} \mathrm{O}$, if the incorrect derivatization reagent is used. The acetate derivative adds more oxygen atoms than remain from the native molecule. The choice to transition to a derivative that adds no $\mathrm{O}$ atoms was made and so we used trimethylsilyl (TMS) carbohydrate derivatives. The TMS derivative contains one fifth to less than one tenth the number of oxygen atoms coming from hydrolysis, reduction and derivatization steps, depending on the source of the specific monosaccharide. However, methods for forming TMS derivatives are not as robust as for making amino sugar derivatives. 
Therefore two methods for carbohydrate derivatization have been developed; alditol acetate derivatives for monosaccharide identification and quantification and TMS derivatives for ${ }^{18} \mathrm{O} /{ }^{16}$ Ostable isotope ratio measurement.

Methods for carbohydrate and lipid detection, quantitation and characterization were developed during this project work. One goal of this project was to develop methods for measuring carbohydrate and fatty acid markers from castor seeds using instrumentation common to analytical chemistry laboratories. The methods for detecting both derivatized fatty acids and carbohydrates utilize GC-MS instrumentation that either exist or can be easily deployed in an analytical laboratory of the end user's choosing.

This work demonstrates two analytical methods for characterizing seed fatty acids and carbohydrates. Integrated with one another, these measurements provide information on if and how a toxin sample was purified. Sample preparations and derivatives analyzed by GC-MS for compound identity and abundance information can readily be reanalyzed by GC-IRMS to provide stable isotope information which may assist in seed sourcing. Taken together, this package of analytical tools could provide forensically useful information on steps used to purify a ricin sample and potentially link the sample with source seeds.

\subsection{Definitions}

1. Ricin chain $\mathbf{A}$ - This is the $\mathrm{N}$-glycosidase $34 \mathrm{kDa}$ catalytic subunit of Ricin which cleaves A4324 of the $28 \mathrm{~S}$ ribosome inhibiting cellular protein synthesis (Amukele et al 2005).

2. Ricin chain $\mathbf{B}$ - This is the $32 \mathrm{kDa}$ lectin subunit of Ricin which binds cell surfaces of a variety of cell types. Its role is to aid in internalization of the catalytic A chain.

3. Ricin Holotoxin - The complete toxin with both A and B chains purified from Ricinus communis having a lethal dose as low as $1 \mu \mathrm{g} / \mathrm{kg}$ body weight. The "select agent" level is possession of $100 \mathrm{mg}$ or more of this toxin. Toxicity of the individual subunits are $>1,000$ fold less toxic than the holotoxin.(4).

4. Castor Seeds - Beans or seeds from the castor plant (Ricinus communis) that are unregulated and widely available through commercial sources (eg. garden supply) as well as used extensively as an agricultural product for purification of castor oil. Ricin is present in the residual "seed mash" present after oil has been extracted. Castor seeds are $40-60 \%$ oil by weight (5). De-fatted seed mash, the remaining $60-40 \%$ of the seed, is composed primarily of carbohydrate and protein ${ }^{14}$. Of this defatted mash, $0.9 \%$ (12) to $1.5 \%$ (6) has been reported to be ricin.

5. Gas chromatography mass spectrometry (GC-MS) - Gas chromatography mass spectrometry. Separation of volatile or semi volatile compounds following heating and a temperature gradient while passing through a capillary column before introduction into a single stage of mass spectrometry. Electron impact ionization allows for identification of the resulting fragmentation pattern of each compound eluting from the column. 
6. Alditol Acetates (AA) Derivatives - Reduced form of common neutral aldose sugars (e.g. glucose or galactose) or amino aldoses derivatized to their acetate form with acetic anhydride. Hydroxyl and amino groups fully derivatized in this form.

7. Trimethylsilyl (TMS) Derivatives - Full derivatization of hydroxyl groups of neutral sugars. Important aspect of this type of derivative is that it does not add or exchange any $\mathrm{O}$ atoms on the final derivative unlike the alditol acetate.

8. Fatty acid methyl ester (FAME) - Derivative form of fatty acids existing as either free fatty acids or freed from phospholipids following saponification. The carboxylic acid group is methylated to create a volatile derivative.

9. Gas chromatography isotope ratio mass spectrometry (GC-IRMS) measurement of elemental stable isotope ratios following separation by GC and conversion to simple gases through pyrolysis or combustion. The conversion to gases allows for monitoring of three specific masses of gas formed.

10. Principle Component Analysis (PCA) - mathematical tool to reduce large data sets to a small number of unrelated variables that explain the variance within that dataset.

11. $\mathbf{C M}$ - castor seed mash sample preparation method.

12. $\mathbf{A E}$ - acetone extracted mash sample preparation method.

13. ESP- Epsom salt protein precipitation castor sample preparation method

14. AP- acetone protein precipitation castor sample preparation method

15. Onalee - seeds obtained from “Onalee’s seeds” in Brooksville FL.

16. PNNL - seeds from plants cultivated in Richland WA.

17. Whatcom - seeds obtained from Whatcom Seed Co. in Eugene OR. Seeds originally cultivated in Darjeeling District of India.

\subsection{Methods}

\subsection{Castor Sample Preparation}

Castor beans from the same cultivar grown in three different geographic regions (climates) were analyzed: Brooksville Florida (purchased from “Onalee’s Seeds”), locally grown at Pacific Northwest National Laboratory (PNNL) in Richland Washington and Darjeeling District of India (Purchased prior to October 2007 from Whatcom Seed Co. of Eugene OR). Four different methods of purification were applied to the three seed types: 1) castor seed mash alone (CM), 2) acetone extraction (AE) of oil from mash alone, 3) Epsom salt protein precipitation (ESP) and 4) acetone precipitation (AP) of proteins from oil-extracted mash.

The methods for preparing castor samples used in the initial investigation are provided in Appendix A. A fourth type of castor seed was obtained from "Bouncing Bear Botanicals" (Flagstaff AZ), however because the growth region for these seeds was not specifically identified (only “a distributor in Italy”) these seeds were used as materials for analytical methods development as either crude or acetone extracted mash. It should be noted that the yield of each method varied in terms of the final sample mass. Both the castor seed mash and acetone extracted mass had high yields, with several hundred mg of sample 
derived from roughly 2 grams of seeds. However the ESP procedure would yield significantly less, where 50 to $100 \mathrm{mg}$ of precipitated material would be produced. The AP procedure would typically yield over twice as much material as the ESP procedure. As a result of the low yield from the ESP procedure, this procedure was not applied to Whatcom seeds because they were in limited supply.

\subsection{Fatty Acid Derivatization Method.}

Standard Operating Procedure for preparing fatty acid methyl ester derivatives is provided in Appendix B. The summary of this method is:

1. This procedure begins with a saponification step to cleave ester bonds and liberate fatty acids (in their ionic form) from lipids, lipoproteins, and lipopolysaccharide. Since ricin can be inactivated by exposure to $0.06 \mathrm{~N} \mathrm{NaOH}$ for 30 minutes at room temperature, this treatment also inactivates any ricin that might be present in the sample.

2. Following saponification, the solutions are acidified, and the re-protonated fatty acids are then extracted into methyl-t-butyl ether (MTBE). The MTBE is evaporated under nitrogen, and when the solution reaches a small volume, it is transferred into a fresh vial for the methylation reaction.

3. The remaining MTBE is evaporated, and the samples are resuspended in $\mathrm{BF}_{3}$ in methanol and incubated to methylate the fatty acids. This step must be anhydrous, as water hydrolyzes the esters.

4. Following methylation, the FAMEs are extracted into hexane and the final volume decreased to $\sim 100 \mu \mathrm{L}$ by evaporation under nitrogen.

5. The solution of FAMEs can be analyzed by standard GC-MS, by GC-FID, or by GCIRMS.

\subsection{Carbohydrate Derivatization Methods}

Standard Operating Procedure for preparing alditol acetate derivatives is provided in Appendix C. The summary of this method is:

1. This method relies on first liberating any bound sugar monomers (e.g. glucose, inositol, arabinose, mannose, etc.) from oligomeric or polymeric structures using acid hydrolysis. Examples of target compounds are the glucose-rich starch, inositol of phospholipids and "cyclitol" disaccharides, xylose/ arabinose rich hemicellulose polymers within the cell wall and the mannose rich protein glycosylation.

2. Following acid hydrolysis, the samples are neutralized using an organic base and hydrophobic contaminants removed by solid phase extraction. The aldose (C-1 carbonyl containing) sugars are then reduced to their alditol form using sodium borodeuteride. The use of the borodeuteride adds a deuterium to the $\mathrm{C}-1$ carbon, 
allowing native aldoses to be distinguished from native alditols in the mass spectrum (i.e.: glucose is distinguishable from glucitol).

3. Following reduction, residual borodeuteride is dried away by addition of methanolacetic acid to create a volatile tetramethyl borate gas. The result is residual sodium and acetate. Derivatization of the reduced sugars can then take place by addition of acetic anhydride to form acetate derivatives which are suitably volatile for GC-MS analysis. Following derivatization, purification steps to remove residual acetic anhydride and any remaining hydrophilic contaminants are used to prepare samples for GC-MS analysis.

4. This method can detect a wide range of neutral and amino carbohydrate markers from as little as $20 \mathrm{mg}$ of sample. Eighteen carbohydrate markers (Table 2) are included in an "external standard" mix that is prepared in triplicate along with each batch of castor samples. Two "internal standards" are included within the external standard mix as well as in each sample.

5. This approach is used for both providing quantitative data on carbohydrate abundance and control for variations in derivatization efficiency, shifts in chromatography, or other factors that may affect the collection and interpretation of data. The standard compounds used for this method are provided in Table 2.

6. This method was not developed with the analysis of acidic sugars in mind, although further alterations may make that possible. The derivatives are anticipated to be stable at $4{ }^{\circ} \mathrm{C}$ for up to a month for reanalysis.

\begin{tabular}{|l|l|}
\hline \multicolumn{1}{|c|}{ Standard } & \multicolumn{1}{c|}{ Type } \\
\hline Fucose & External \\
\hline Rhamnose & External \\
\hline Ribose & External \\
\hline Arabinose & External \\
\hline Deoxyglucose & External \\
\hline Xylose & External \\
\hline Methylglucose & $\begin{array}{l}\text { Internal (for neutral } \\
\text { sugars) }\end{array}$ \\
\hline Pinitol (3-O-Methyl chiro-inositol) & External \\
\hline Chiro-inositol & External \\
\hline Myo-inositol & External \\
\hline Allo-inositol & External \\
\hline Muco-inositol & External \\
\hline Scyllo-inositol & External \\
\hline Mannose & External \\
\hline Galactose & External \\
\hline Glucose & External \\
\hline N-methyl glucamine & $\begin{array}{l}\text { Internal (for amino } \\
\text { sugars) }\end{array}$ \\
\hline Mannosamine & External \\
\hline Glucosamine & External \\
\hline Galactosamine & External \\
\hline & \\
\hline
\end{tabular}

Table 2 Monosaccharide standards used. 
Standard Analytical Method for preparing TMS derivatives is provided in Appendix D. The summary of this method is:

1. This method relies on first liberating any bound sugar monomers (e.g. glucose, inositol, arabinose, mannose, etc.) from oligomeric or polymeric structures using acid hydrolysis. Examples of target compounds are the glucose-rich starch, inositol of phospholipids and "cyclitol" disaccharides, xylose/ arabinose rich hemicellulose polymers within the cell wall and the mannose rich protein glycosylation.

2. Following acid hydrolysis, the samples are neutralized using an organic base and hydrophobic contaminants removed by solid phase extraction. The aldose (C-1 carbonyl containing) sugars are then reduced to their alditol form using sodium borodeuteride. The use of the borodeuteride adds a deuterium to the C-1 carbon, allowing native aldoses to be distinguished from native alditols in the mass spectrum (glucose is distinguishable from glucitol).

3. Following reduction, the residual borodeuteride is removed by addition of methanolacetic acid to create volatile tetramethyl borate gas. The remainder is sodium acetate.

4. Derivatization of the reduced sugars to their trimethylsilyl form can then take place by resuspending them in pyridine and adding the $\mathrm{N}, \mathrm{O}$-bis

(Trimethylsilyl)trifluoroacetamide (BSTFA) with Trimethylchlorosilane (TCMS) derivatizing reagent. Following a short, room-temperature, incubation step the products are ready for direct analysis by GC-MS.

5. This method can detect a wide range of neutral carbohydrates (listed in Table 3) from as little as $20 \mathrm{mg}$ of sample. This method was not developed with the analysis of amino or acidic sugars in mind, although further alterations may make that possible in the future. The derivatives are anticipated to be stable at $4{ }^{\circ} \mathrm{C}$ for up to a month for reanalysis.

\begin{tabular}{|l|l|}
\hline \multicolumn{1}{|c|}{ Standard } & \multicolumn{1}{c|}{ Type } \\
\hline Fucose & External \\
\hline Rhamnose & External \\
\hline Ribose & External \\
\hline Arabinose & External \\
\hline Deoxyglucose & External \\
\hline Xylose & External \\
\hline Methylglucose & Internal (for neutral \\
& sugars) \\
\hline Pinitol (3-O-Methyl chiro-inositol) & External \\
\hline Chiro-inositol & External \\
\hline Myo-inositol & External \\
\hline Allo-inositol & External \\
\hline Muco-inositol & External \\
\hline Scyllo-inositol & External \\
\hline Mannose & External \\
\hline Galactose & External \\
\hline Glucose & External \\
\hline
\end{tabular}

Table 3 Standard monosaccharides used for TMS derivatization. 


\subsection{Gas Chromatography Mass Spectrometry Data Acquisition}

1. Data Acquisition and interpretation is also described in Appendices B-D.

2. Analysis of the alditol acetate derivatized carbohydrates was performed on the Agilent Technologies 7890A/5975C GC-MS instrument equipped with a CTC CombiPAL autosampler system.

a. The system is equipped with a HP-5 column (Agilent Technologies., $250 \mu \mathrm{m} x$ $0.25 \mu \mathrm{m} \times 30 \mathrm{~m}$ ) to effectively separate the alditol acetate mixtures.

b. Samples were injected into a split/splitless injector operated in split mode using a10:1 split ratio with $10.8 \mathrm{~mL} / \mathrm{min}$ split flow, $1.08 \mathrm{~mL} / \mathrm{min}$ column flow, $\mathrm{He}$ carrier gas.

c. The injector temperature was held at $250^{\circ} \mathrm{C}$ and the transfer line at $250^{\circ} \mathrm{C}$. The GC oven was held at $100^{\circ} \mathrm{C}$ for $1 \mathrm{~min}$, then ramped at $2.5^{\circ} \mathrm{C} / \mathrm{min}$ to $225^{\circ} \mathrm{C}$, then ramped at $25^{\circ} \mathrm{C} / \mathrm{min}$. with a hold for $5 \mathrm{~min}$.

d. The ion source temperature was $230^{\circ} \mathrm{C}$ with electron impact ionization energy of $-70 \mathrm{~V}$. Following a $10 \mathrm{~min}$ delay, data was collected from $35 \mathrm{~m} / \mathrm{z}$ to $250 \mathrm{~m} / \mathrm{z}$ using a detector voltage of 1059V.

3. Analysis of the FAMES samples was performed on the same Agilent Technologies 7890A/5975C GC-MS described above.

a. The analyses were also performed using an HP-5 column (Agilent Technologies., $250 \mu \mathrm{m} \times 0.25 \mu \mathrm{m} \times 30 \mathrm{~m})$.

b. Samples were injected into a split/splitless injector operated in pulsed splitless mode, with $1.08 \mathrm{~mL} / \mathrm{min}$ column flow, He carrier gas.

c. The injector temperature was held at $280^{\circ} \mathrm{C}$ and the transfer line at $250^{\circ} \mathrm{C}$. The GC oven was held at $35^{\circ} \mathrm{C}$ for $21 \mathrm{~min}$, then ramped at $25^{\circ} \mathrm{C} / \mathrm{min}$ to $150^{\circ} \mathrm{C}$, then ramped at $10^{\circ} \mathrm{C} / \mathrm{min}$ to $280{ }^{\circ} \mathrm{C}$ with a hold for $1.4 \mathrm{~min}$.

d. The ion source temperature was $230^{\circ} \mathrm{C}$ with ionization energy of $-70 \mathrm{~V}$. Following a $5 \mathrm{~min}$ delay, data was collected from $50 \mathrm{~m} / \mathrm{z}$ to $550 \mathrm{~m} / \mathrm{z}$ using a detector voltage of $1059 \mathrm{~V}$.

4. The response factor of each of compounds (i.e. the external standards, exstd) was determined by dividing the peak area of the external standard by the peak area of the internal standard, Equation [1].

a. The neutral target monosaccharides fucose, rhamnose, ribose, arabinose, deoxyglucose, xylose, mannose, galactose and glucose were compared to the internal standard methylglucose.

b. The targeted amino monosaccharides mannosamine, glucosamine and galactosamine were compared to the internal standard n-methylglucamine.

c. An averaged response factor for each external standard was determined by averaging the response factors for each standard mix analyzed within a sample set.

$$
R F_{\text {std }}=\frac{\text { Area }_{\text {extstd }}}{\text { Area }_{\text {int std }}} \quad \text { Equation [1] }
$$


d. Response factors for processed bean carbohydrates were calculated by dividing the peak area of the carbohydrate peak (carbpeak) by the peak area of the internal standard, Equation [2]

$$
R F_{\text {sample }}=\frac{\text { Area }_{\text {carbpeak }}}{\text { Area }_{\mathrm{int} \mathrm{std}}} \quad \text { Equation [2] }
$$

e. The mass of each carbohydrate in the sample was calculated based on the carbohydrate response factor in the sample as compared to the response factor for $60 \mathrm{ng} / \mu \mathrm{L}$ of carbohydrate in the standard, multiplied by the sample volume to determine the total amount of each known carbohydrate in the sample, Equation [3].

$$
\text { mass }_{\text {carb }}=\frac{\left(\text { conc }_{\text {std }}\right)\left(\text { vol }_{\text {std }}\right)\left(R F_{\text {sample }}\right)\left(v_{\text {sol }} \text { sample }_{1}\right)}{\left(R F_{\text {std }}\right)\left(v_{\text {inj }}\right)}
$$

\section{Equation [3]}

f. Where:

$\mathrm{conc}_{\text {std }}=$ the concentration of the known standard in the standard mix in ng/ $\mu \mathrm{L}$ $\mathrm{Vol}_{\text {std }}=$ the volume of standard mix injected $\mathrm{Vol}_{\text {sample }}=$ the total sample volume of the final derivatized sample Mass $_{\text {carb }}=$ mass of the known carbohydrate in the final sample in nanograms.

g. Finally, the \% weight of each carbohydrate in the sample can be calculated if needed by Equation [4]

$$
\% w t=\frac{\text { mass }_{\text {carb }}}{\text { mass }_{\text {sample }}} \times 100
$$

Equation [4]

\subsection{Isotope Ratio Mass Spectrometry Analysis of Methyl Ricinoleate}

1. Stable isotope analysis of $\mathrm{MR}$, the derivatization product of ricinoleic acid.

a. Stable isotope analysis used a Thermo Trace GC Ultra in-line with a Thermo GCC to a Thermo Delta V Plus isotope ratio mass spectrometer.

$b$. The continuous flow system employed GC separation of MR from all other contaminants and then passed the MR sequentially through a pyrolysis reactor (at1440 ${ }^{\circ} \mathrm{C}$ ), a dryer for water removal, and then directly into the mass spectrometer.

c. Separation of MR on the GC used a Restek Rtx-1ms, 60m, $0.25 \mathrm{~mm}$ ID, $0.25 \mu \mathrm{m}$ film thickness column (Bellefonte, PA, USA).

d. A constant flow of $1.5 \mathrm{~mL}$ per minute helium was used in the column. A splitless surge injection, splitless time of 1.00 minute and a subsequent split flow of $11 \mathrm{~mL}$ per minute was used. Injector temperature was maintained at $300{ }^{\circ} \mathrm{C}$. 
e. Oven temperature was initially held at $110^{\circ} \mathrm{C}$ for one minute then ramped to 320 ${ }^{\circ} \mathrm{C}$ at $12{ }^{\circ} \mathrm{C} /$ minute and held at temperature for eight minutes.

2. Stable isotope data was collected in real time as the MR pyrolysis products (namely $\mathrm{H}_{2}$ ) were eluted into the mass spectrometer. Three types of standards were employed to ensure data viability and day to day stability.

a. First, three reference pulses of research purity molecular hydrogen were included at the initiation and termination of every chromatogram to ensure mass spectrometer response stability and to provide intra-run calibration for the observed sample-derived peaks.

b. Secondly, an externally calibrated alkane mixture (mixture B2 available from Arndt Schimmelman, University of Indiana, Bloomington, IN, USA) was run at least once a day to calibrate the system. Importantly, this mixture was run through the GC and therefore tested the entire measurement process, from chromatographic separation through pyrolytic conversion to $\mathrm{H}_{2}$ and finally to isotope measurement in the mass spectrometer.

c. Finally, an in-house standard containing purchased methyl palmitate and methyl ricinoleate (Sigma, St. Louis, MO, USA) were used dissolved in methanol. This standard was run between samples throughout the day and used to alert against any system drift over the course of multiple sample runs.

d. MR samples were run in a methanol solvent and adjusted solvent levels to ensure MR responses fell within the mass spectrometer linear range.

e. A minimum of three replicates of all samples are run, including duplicate injections of each sample, on at least two different days as a check of sample reproducibility and as a further guard against instrument drift over time. Integration and peak identification parameters were identical for the standard and sample runs.

\subsection{Results}

\subsection{Fatty Acid Analysis}

\section{Gas Chromatography Flame Ionization Detection (GC-FID)}

A purchased MR standard was purchased for method development to ensure accurate, reproducible results. Sample injection onto the GC column was evaluated using hexane, chloroform and methanol as injection solvents. This was evaluated using two different GC instruments including one with a flame ionization detector (FID) as well one with an electron impact (EI) ionization mass spectrometry (MS) detector. Peak reproducibility was highest using methanol as the final solvent on both instruments.

\section{Gas Chromatography Mass Spectrometry (GC-MS)}

The response linearity was also evaluated on both the GC-FID and the GC-MS system. An example of the standard curve data for MR from the GC-MS system is given in 
Figure 2. The linearity of the response $\left(\mathrm{R}^{2}\right.$ values of greater than 0.998$)$ indicated that semi quantitative information could be obtained using a comparison to data collected on a MR standard within the same run as castor samples. MR linearity was similar on both detectors so we used the GC-MS system which combined concentration output with peak identification from the mass spectrum.

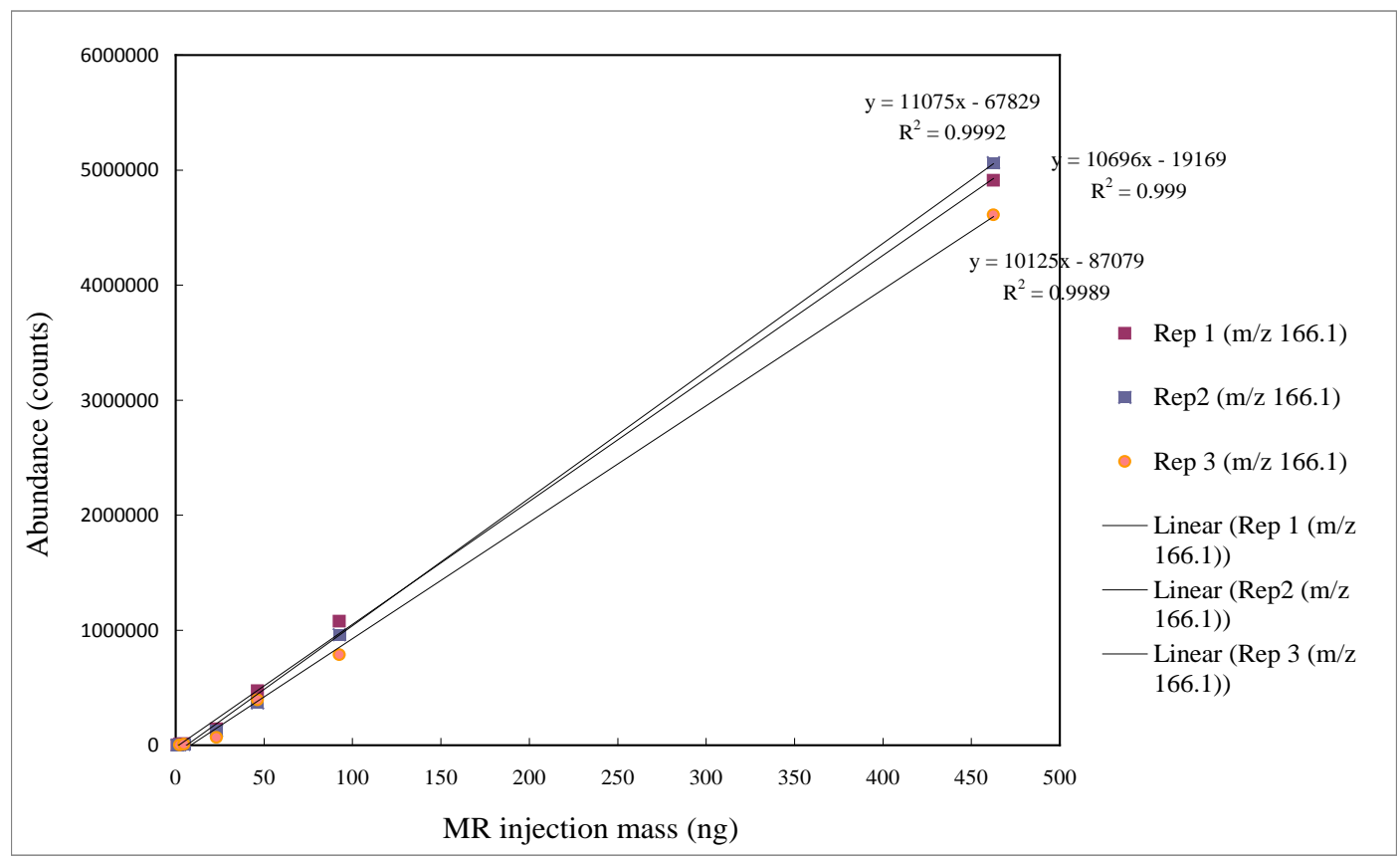

Figure 2 Graph of MR response. Amounts ranging from 0.9 to 462.5 ng injected on column using three different replicate injections for each concentration.

The preparation of FAMEs from castor samples for this study proceeded using six samples per batch with castor samples from each recipe and seed type represented in each batch. Analysis of the FAME samples by GC-MS proceeded in a randomized order with blank methanol injections between samples to ensure there was no sample carryover. An example chromatogram and mass spectrum is given in Figure 3. 
Combined Castor Marker and Isotope Profile for Ricin Forensics: Final Report

Page 17 of 57

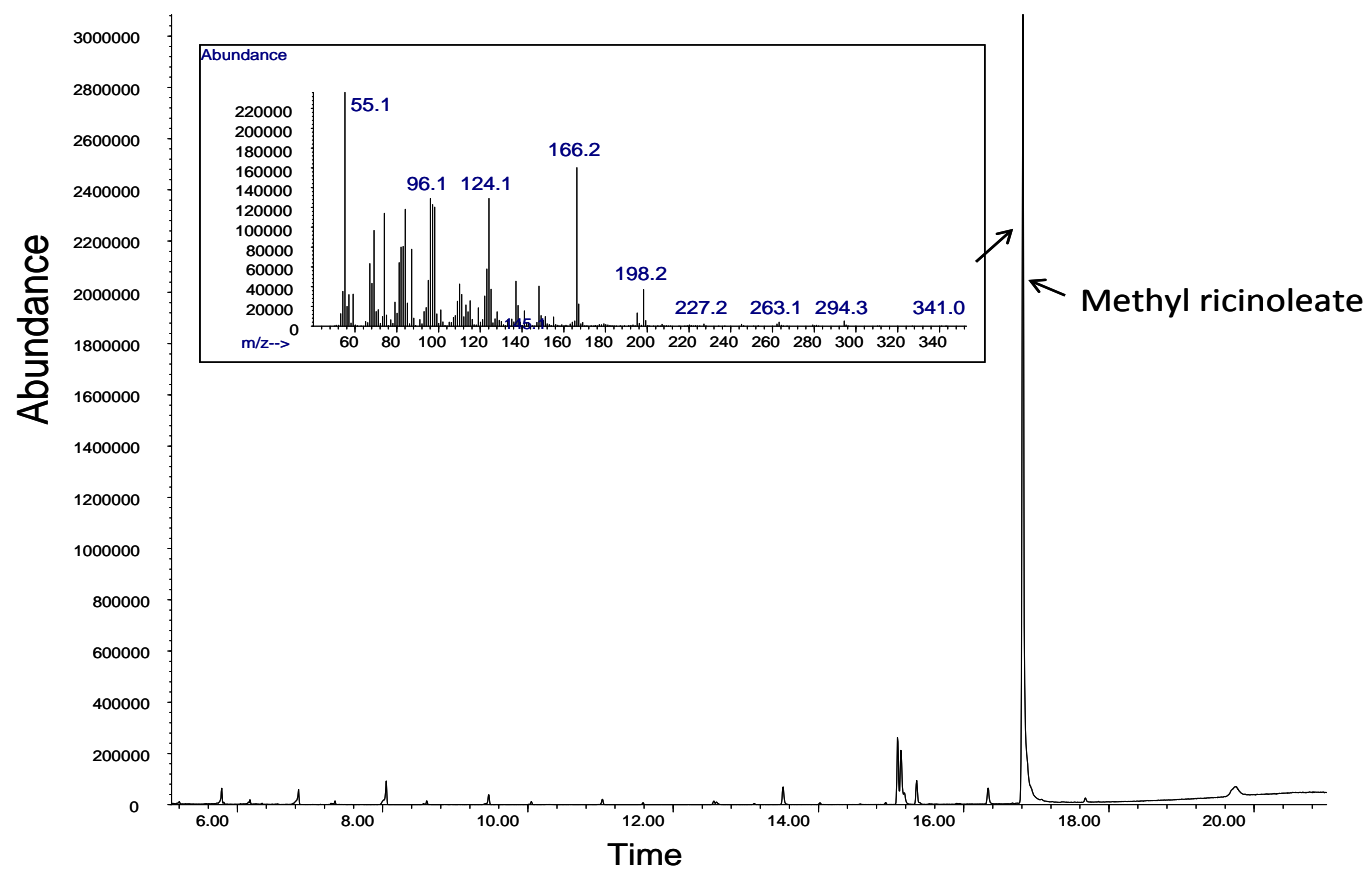

Figure 3. Chromatogram of FAME prepared from crude mash sample. Samples diluted 1:100 in methanol demonstrate the major peak of MR with baseline resolution. Inset shows electron impact mass spectrum of the MR.

MR abundance systematically varied between samples from the different castor preparation types. The CM samples clearly contained the highest MR content while the AP samples contained near background amounts of MR. The differences in \% weight of MR between preparations are seen in figure 4. One data point was excluded for a PNNL ESP sample. This sample was determined to be an outlier using Dixon's Q test at the $90 \%$ confidence interval. 


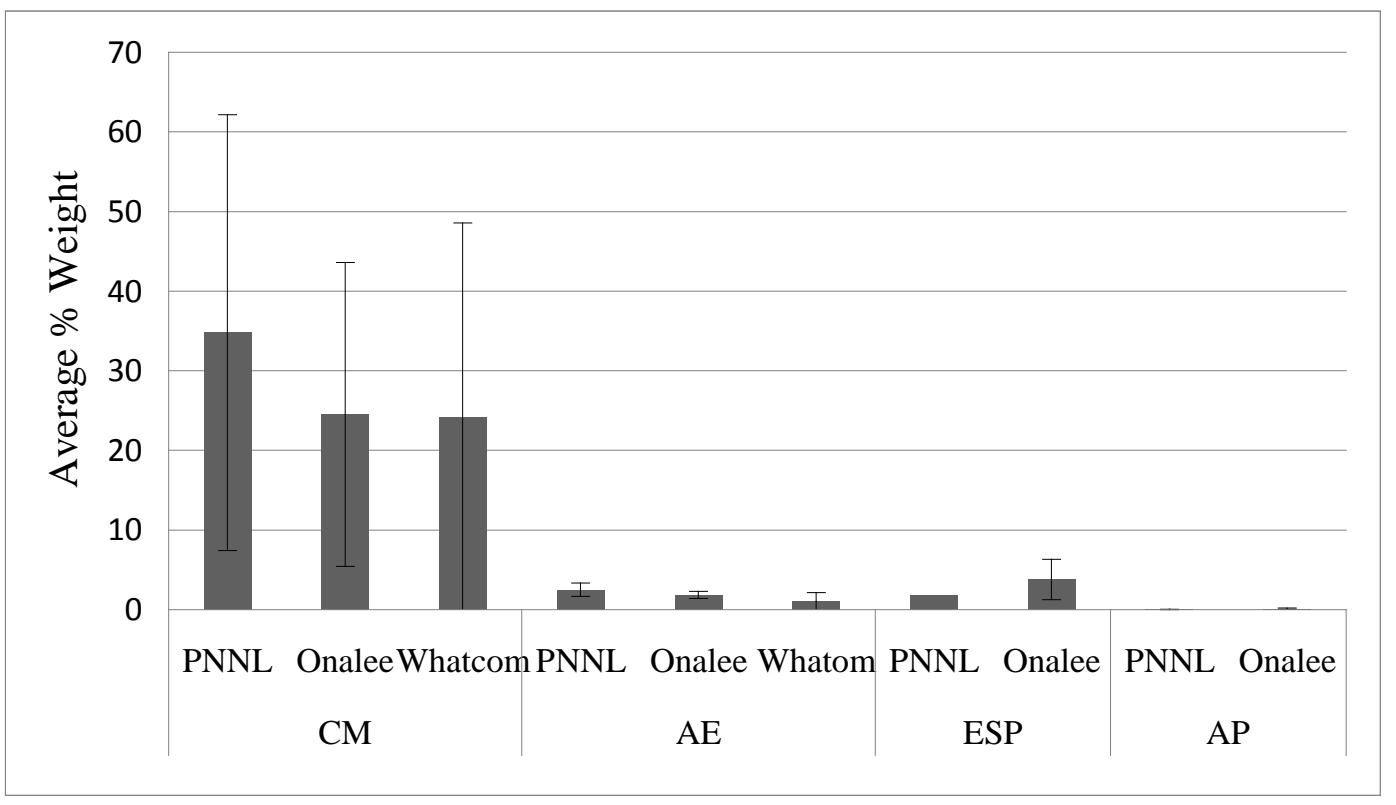

Figure 4 Graph of MR content. MR measured in four sample preparation types applied to three sources of castor seeds. The three seed sources are indicated for each type or preparation: PNNL (Richland WA), Onalee (Brooksville FL), Whatcom (Darjeeling India).

One explanation for the outlier data point may lie in sample heterogeneity. This heterogeneity may exist at the level of the sample or during the derivatization method. MR is not as soluble in hexanes as other solvents, such as methanol, and samples dissolved in hexanes showed poor reproducibility in our early tests. To optimize sample reproducibility we evaporated off all hexanes (using a helium stream) and resuspended the samples in methanol. This modification from typical FAME procedures highlights the structural uniqueness of MR from other FAMEs. Sample heterogeneity during extraction or solvent transition may have impacted these results. Further refinement of the method will examine this issue.

Despite observed variability, there is a clear distinction between crude castor seed mash and samples prepared by either acetone extraction or the two precipitation methods. With one exception, the mash had at least $9 \%$ MR by weight (and more often over 20\%) whereas no other preparation type yielded more than $4 \%$ MR by weight. The numerical values can be found in (Table 4).

\begin{tabular}{rrrrrrrrrrr} 
& \multicolumn{3}{c}{ Castor Seed Mash } & \multicolumn{3}{c}{ Acetone Extracted } & \multicolumn{2}{c}{ Epsom Salt ppt } & \multicolumn{2}{c}{ Acetone ppt } \\
& PNNL & Onalee & Whatcom & PNNL & Onalee & Whatcom & PNNL & Onalee & PNNL & Onalee \\
Ave \% & 34.80 & 24.54 & 35.36 & 2.50 & 1.86 & 1.04 & 1.88 & 3.79 & 0.03 & 0.13 \\
$\begin{array}{r}\text { Weight } \\
\text { Std }\end{array}$ & 27.35 & 19.09 & 20.91 & 0.84 & 0.42 & 1.11 & n/a & 2.55 & 0.01 & 0.06 \\
Dev. & & & & & & & & & &
\end{tabular}

Table 4 average \% weight and standard deviation of methyl ricinoleate. 


\section{Gas Chromatography Isotope Ratio Mass Spectrometry (GC-IRMS)}

FAME samples prepared from each of the above seed sources and toxin preparation methods were analyzed for their D/H by GC-IRMS following GC-MS analysis. The MR content of the AP prepared samples was below the analysis limit of the IRMS system so was not measured. D/H of each of the other samples was measured (Figure 5).

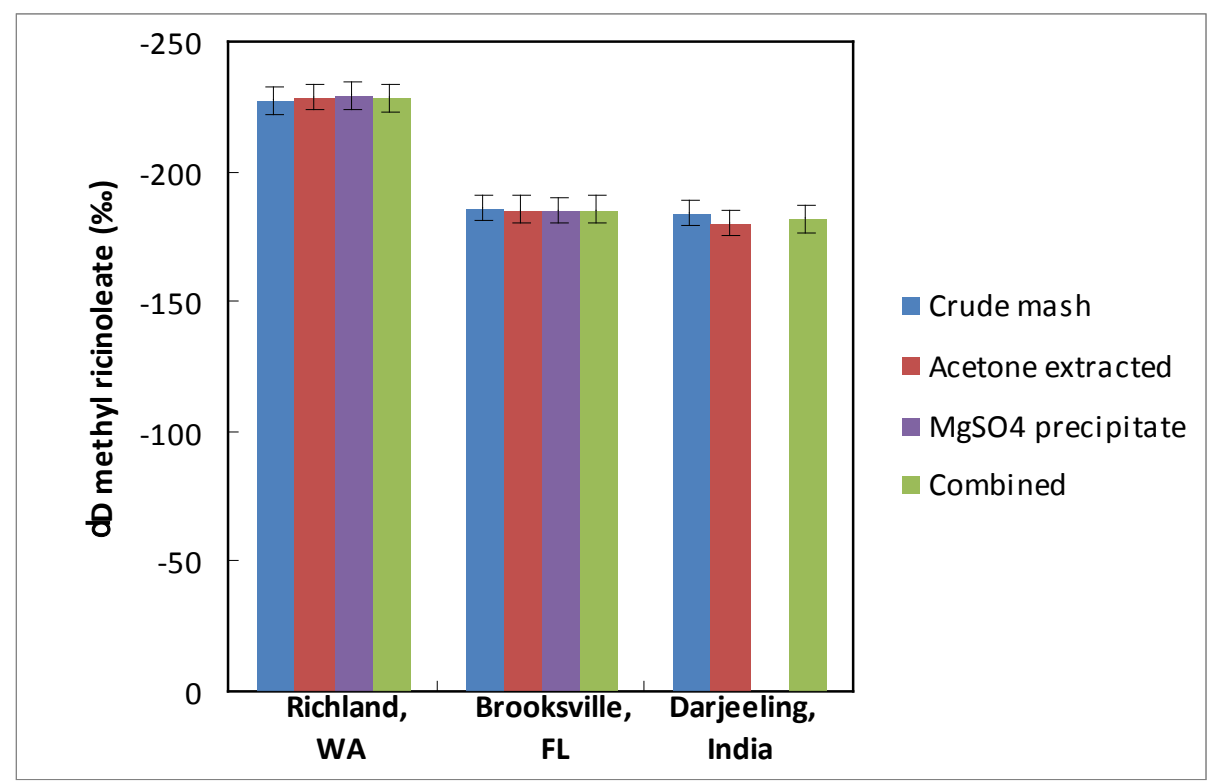

Figure 5 Graph of $\mathrm{D} / \mathrm{H}$ isotope ratios. Data expressed in ppm from standard materials for three seed sources labeled for source and geographic location. The preparation type used for the measurement is color coded and error bars representing one standard deviation are included. The combined ratio measurement is the average value for all preparations for that seed source.

The MR isotope ratio measurements show close correlation the bean source and are independent of toxin preparation method. For instance, a clear distinction can be made between the Richland (PNNL) and Brooksville (Onalee) or Darjeeling (Whatcom) seed sources. However, significant similarity is seen between the $\mathrm{D} / \mathrm{H}$ ratios for Brooksville and Darjeeling seeds, illustrating that caution must be used while interpreting this data as seeds from distinct locations may have similar $\mathrm{D} / \mathrm{H}$.

\subsection{Carbohydrate Analysis}

\section{Alditol Acetate Derivative Abundance}

The abundance and identity of eighteen carbohydrates (derivatized into their alditol acetate form) was measured using GC-MS. The GC separation was sufficient to resolve all standard compounds present in a mixture labeled external standards. Eleven of the 
eighteen carbohydrates were found in one or more type of castor preparation: rhamnose, ribose, fucose, arabinose, xylose, chiro-inositol, myo-inositol, mannose, glucose, galactose, glucosamine. The percent dry weight of each is calculated using the method described above and first measured for replicate samples of (inactivated) toxin preparations.

A standard practice in this work was to analyze samples from heat inactivated castor seeds. The goal was to reduce the hazard of working with the material and reduce inventory of active toxin and permit analysis outside the select agent laboratory. To proceed with this approach, however, we needed to confirm that heat inactivation of ricin did not alter carbohydrate content. CM and AE samples were prepared using seeds obtained from "Bouncing Bear". Bar graph data of the carbohydrate content from CM vs. AE samples is provided in Figure 6. Heat inactivation at $100{ }^{\circ} \mathrm{C}$ for 60 min was performed on one set of seeds and not the other. The affect of heat inactivation was assessed by comparing the inactivated and native seeds for castor seed mash preparations of each (Figure 7).

The native CM samples had slightly higher amounts of each monosaccharide than the inactivated CM samples. However these differences were within one standard deviation of each other. The AE samples had more significant differences with increased abundance of each monosaccharide. In all cases, the relative abundance profiles of carbohydrates remained consistent between sample treatments (Table 5).

\begin{tabular}{|c|c|c|c|c|c|c|c|c|}
\hline & \multicolumn{2}{|c|}{$\begin{array}{l}\text { Castor seed Mash } \\
\qquad(\mathrm{CM})(\mathrm{n}=3)\end{array}$} & \multicolumn{2}{|c|}{$\begin{array}{l}\text { Acetone Extracted } \\
\text { (AE) Mash }(n=3)\end{array}$} & \multicolumn{2}{|c|}{$\begin{array}{l}\text { Inactivated CM } \\
\qquad(\mathrm{n}=2)\end{array}$} & \multicolumn{2}{|c|}{$\begin{array}{l}\text { Native CM } \\
\quad(\mathrm{n}=3)\end{array}$} \\
\hline & $\begin{array}{l}\text { \% Sample } \\
\text { Wt. }\end{array}$ & Std. Dev. & $\begin{array}{c}\% \\
\text { Sample } \\
\text { Wt. }\end{array}$ & $\begin{array}{l}\text { Std. } \\
\text { Dev. }\end{array}$ & $\begin{array}{c}\% \\
\text { Sample } \\
\text { Wt. }\end{array}$ & Std. Dev. & $\begin{array}{c}\% \\
\text { Sample } \\
\text { Wt. }\end{array}$ & $\begin{array}{l}\text { Std. } \\
\text { Dev. }\end{array}$ \\
\hline Rhamnose & 0.31 & 0.02 & 0.54 & 0.03 & 0.31 & 0.10 & 0.41 & 0.08 \\
\hline Ribose & 0.04 & 0.04 & 0.00 & 0.00 & 0.02 & 0.03 & 0.03 & 0.04 \\
\hline Fucose & 0.17 & 0.05 & 0.34 & 0.02 & 0.10 & 0.03 & 0.17 & 0.03 \\
\hline Arabinose & 1.76 & 0.04 & 2.56 & 0.33 & 1.31 & 0.19 & 1.60 & 0.23 \\
\hline Xylose & 1.07 & 0.28 & 1.66 & 0.09 & 0.72 & 0.21 & 0.97 & 0.18 \\
\hline $\begin{array}{l}\text { chiro- } \\
\text { Inositol }\end{array}$ & 0.15 & 0.03 & 0.24 & 0.02 & 0.16 & 0.00 & 0.15 & 0.06 \\
\hline myo-Inositol & 1.08 & 0.16 & 2.61 & 0.26 & 0.91 & 0.07 & 1.30 & 0.36 \\
\hline Mannose & 0.49 & 0.07 & 0.88 & 0.09 & 0.28 & 0.01 & 0.42 & 0.05 \\
\hline Glucose & 3.45 & 0.55 & 5.70 & 0.65 & 3.64 & 0.40 & 4.28 & 0.89 \\
\hline Galactose & 2.08 & 0.22 & 2.62 & 0.30 & 1.81 & 0.01 & 2.28 & 0.54 \\
\hline Glucosamine & 0.07 & 0.01 & 0.10 & 0.02 & 0.09 & 0.03 & 0.10 & 0.01 \\
\hline
\end{tabular}

Table 5 Comparison of carbohydrate content from active and inactive sample. Sample weight (in \% weight) and standard deviation for bouncing bear seeds prepared as $\mathrm{CM}$ or AE mash from inactivated castor seeds prepared April 2009. A second comparison of inactivated CM was made with "native" CM in the right hand columns. 


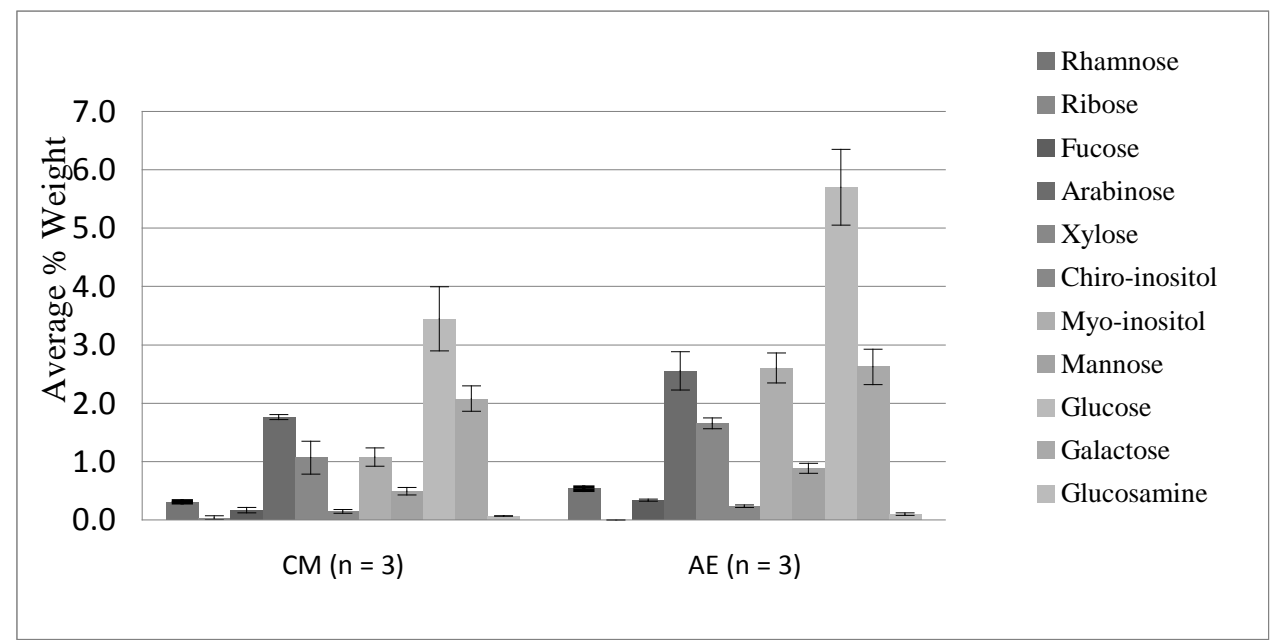

Figure 6. Bar graph comparing first two preparation types. Bar graph depicting \% sample weight with error bars (standard deviation) indicated for each detected marker in the CM vs. AE.

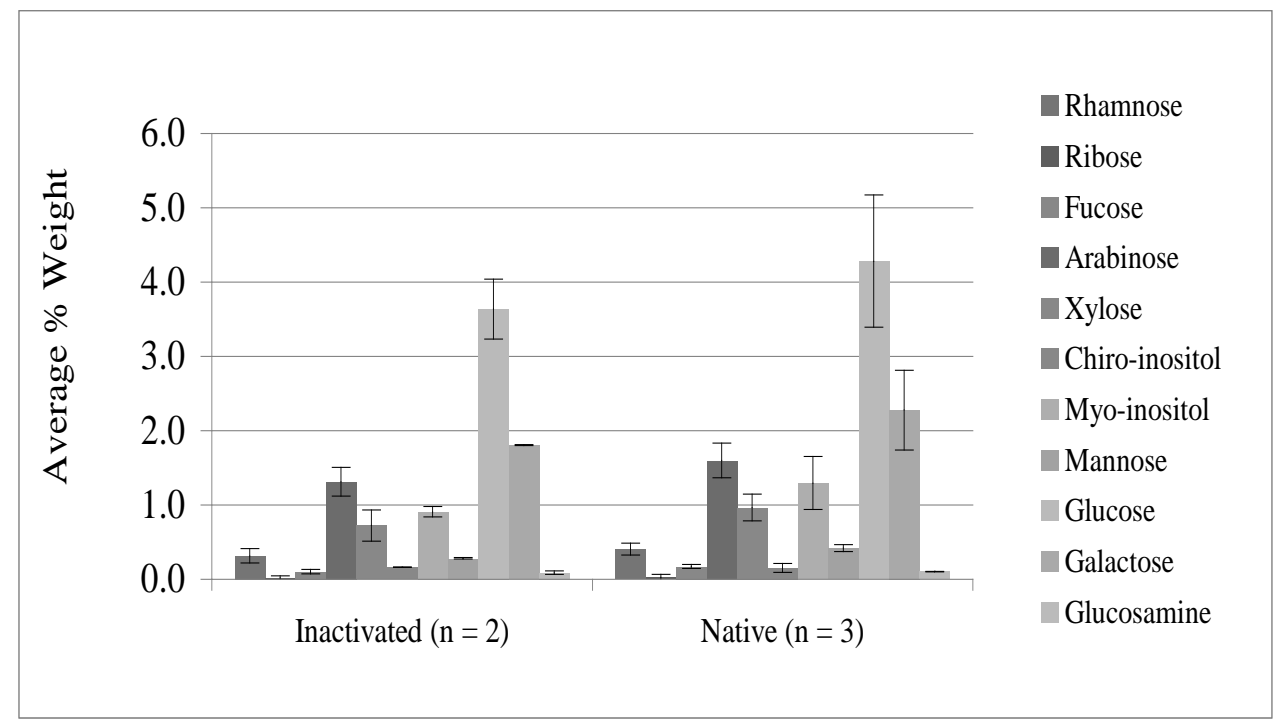

Figure 7 Comparison of active vs. inactivated samples. Bar graph depicting \% sample weight with error bars (standard deviation) indicated for each detected marker for the Native CM (left) vs. the heat inactivated CM (right).

In order to estimate carbohydrate abundance and variability in carbohydrate measurements, five replicate samples were derivatized into their alditol acetate form. Samples prepared from the "Bouncing Bear" seeds using a larger number of replicates for the two different recipes previously examined: $\mathrm{CM}$ and $\mathrm{AE}$ samples. Each recipe was used to prepare samples on two different dates labeled February 2009 and April 2009. The April 2009 samples were used in the comparison of native vs. inactivated samples.

Five aliquots of each sample were derivatized for GC-MS analysis for each recipe type and date (Table 6 and figure 8). Differences between the two preparation recipes were 
seen for the abundance of most carbohydrates with a two-fold increase for the AE samples over the CM samples. This is consistent with the previous observation. Importantly, the \% dry weight of each component was consistent within recipe types prepared on the two different dates.

\begin{tabular}{ccccccccc} 
& \multicolumn{2}{c}{ Feb CM $(\mathrm{n}=5)$} & \multicolumn{2}{c}{ Feb AE $(\mathrm{n}=5)$} & \multicolumn{2}{c}{ Apr CM $(\mathrm{n}=4)$} & \multicolumn{2}{c}{ Apr AE $(\mathrm{n}=5)$} \\
& \% Dry & Std & \% Dry & Std & \% Dry & Std Dev & \% Dry & Std Dev \\
& Weight & Dev & Weight & Dev & Weight & & Weight & \\
Rhamnose & 0.56 & 0.22 & 1.43 & 0.19 & 0.54 & 0.19 & 1.07 & 0.24 \\
Ribose & 0.09 & 0.023 & 0.03 & 0.07 & 0.08 & 0.03 & 0.00 & 0.00 \\
Fucose & 0.22 & 0.08 & 0.65 & 0.12 & 0.20 & 0.07 & 0.70 & 0.04 \\
Arabinose & 2.51 & 0.64 & 6.76 & 0.92 & 2.53 & 0.53 & 6.61 & 0.70 \\
Xylose & 1.42 & 0.43 & 3.70 & 0.46 & 1.21 & 0.34 & 3.56 & 0.58 \\
chiro-inositol & 0.20 & 0.06 & 0.52 & 0.08 & 0.18 & 0.07 & 0.52 & 0.06 \\
myo-inositol & 1.32 & 0.28 & 3.08 & 0.56 & 1.17 & 0.37 & 3.34 & 0.32 \\
Mannose & 0.51 & 0.18 & 1.17 & 0.13 & 0.44 & 0.07 & 1.63 & 0.34 \\
Glucose & 4.53 & 1.47 & 9.21 & 1.33 & 3.54 & 0.96 & 10.94 & 1.04 \\
Galactose & 2.36 & 0.79 & 5.84 & 0.96 & 2.23 & 0.66 & 6.20 & 0.55 \\
Glucosamine & 0.17 & 0.03 & 0.37 & 0.03 & 0.16 & 0.05 & 0.30 & 0.02
\end{tabular}

Table 6. Table comparing castor samples prepared at distinct times. Carbohydrate profiles from crude mash (CM) and acetone extracted (AE) samples from the February (Feb) and April (Apr) preparations. The number of samples in each group is provided in parenthesis.

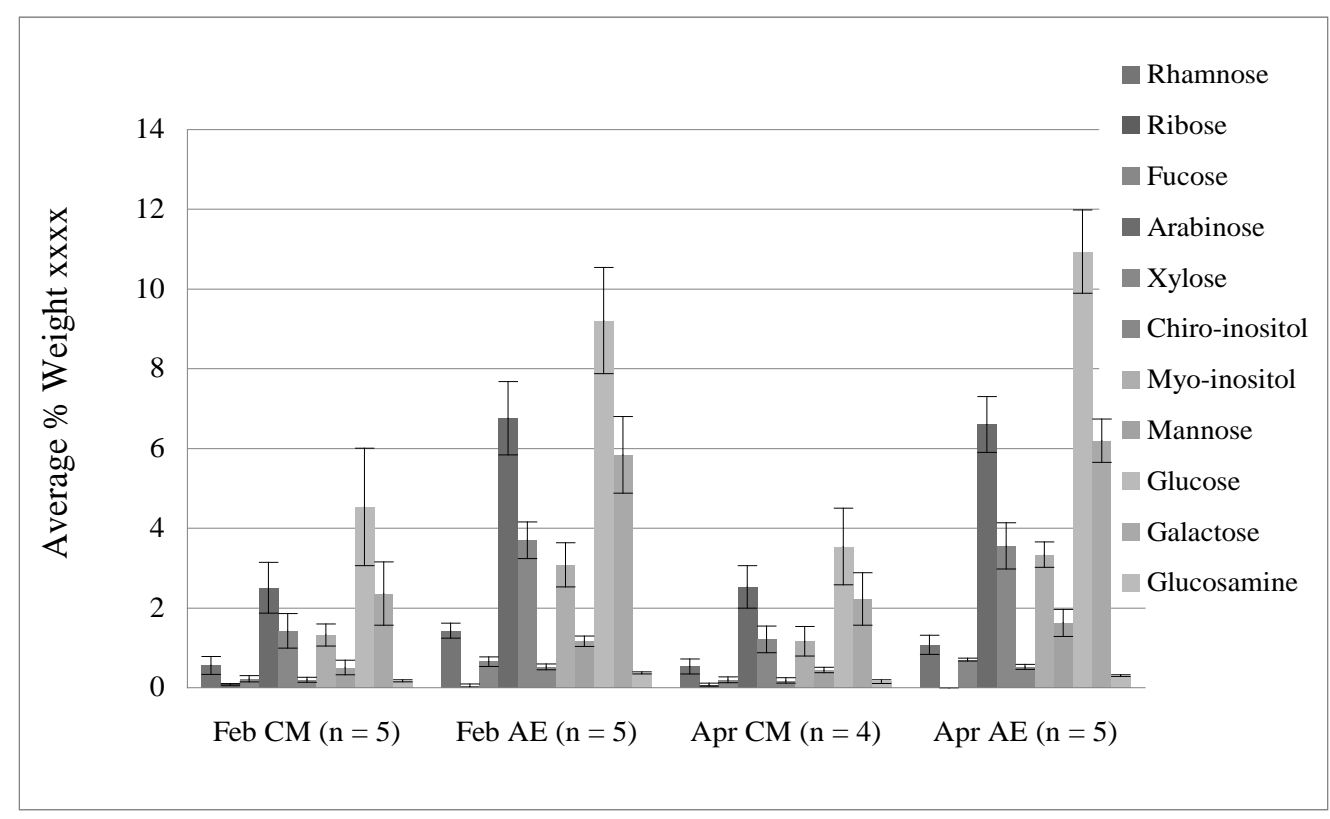

Figure 8. Graph comparing castor samples prepared at different times. Comparison of carbohydrate profiles from CM and AE samples from February (Feb) 2009 and April (Apr) 2009 preparations. The number of samples in each group is provided in parenthesis. Each of the detected markers is color coded (legend at right) with standard deviation bars included. 
The Onalee (O), Whatcom (W) and PNNL (P) sources of castor seeds were used to prepare samples using four distinct methods: CM, AE, ESP and AP. Significant differences in monosaccharide abundance were seen between the CM and AE samples relative to the two precipitation methods ESP and AP (table 7, figure 9). Further differences were evident between the two precipitates sample types. A limited supply of Whatcom seeds grown in a geographically constrained location in India prevented us from performing the precipitation methods (AP, ESP) on the Whatcom samples.

\begin{tabular}{cccccccccccc}
$\begin{array}{c}\text { Average \% } \\
\text { weight }\end{array}$ & \multicolumn{1}{c}{ Crude Mash (CM) } & \multicolumn{4}{c}{ Acetone Extract (AE) } & \multicolumn{3}{c}{$\begin{array}{c}\text { Acetone } \\
\text { Precipitate }\end{array}$} & \multicolumn{2}{c}{$\begin{array}{c}\text { Epsom Salts } \\
\text { Precipitate } \\
\text { (ESP) }\end{array}$} \\
& $\mathrm{P}$ & $\mathrm{O}$ & $\mathrm{W}$ & $\mathrm{P}$ & $\mathrm{O}$ & $\mathrm{W}$ & $\mathrm{P}$ & $\mathrm{O}$ & $\mathrm{P}$ & $\mathrm{O}$ \\
Rhamnose & 0.45 & 0.55 & 0.39 & 1.86 & 1.84 & 1.54 & 0.24 & 0.34 & 0.12 & 0.12 \\
Ribose & 0.01 & 0.10 & 0.05 & 0.08 & 0.08 & 0.16 & 0.09 & 0.20 & 0.00 & 0.09 \\
Fucose & 0.13 & 0.18 & 0.15 & 0.60 & 0.62 & 0.62 & 0.30 & 0.31 & 0.05 & 0.00 \\
Arabinose & 2.35 & 2.79 & 2.08 & 8.93 & 8.73 & 7.94 & 1.01 & 1.62 & 0.77 & 0.42 \\
Xylose & 1.15 & 1.28 & 1.20 & 2.37 & 4.38 & 4.23 & 0.45 & 0.92 & 0.34 & 0.15 \\
chiro- & & & & & & & & & & \\
inositol & 0.02 & 0.07 & 0.06 & 0.09 & 0.07 & 0.42 & 0.38 & 0.49 & 0.00 & 0.00 \\
myo-inositol & 0.57 & 1.30 & 0.74 & 2.24 & 3.21 & 2.08 & 5.21 & 8.11 & 0.13 & 0.17 \\
Mannose & 0.39 & 0.57 & 0.50 & 1.70 & 1.83 & 1.81 & 3.73 & 3.37 & 0.14 & 0.12 \\
Glucose & 3.29 & 7.89 & 4.22 & 13.68 & 21.11 & 11.90 & 8.33 & 12.86 & 2.15 & 1.28 \\
Galactose & 1.43 & 2.38 & 1.52 & 6.18 & 6.37 & 5.32 & 7.76 & 10.53 & 0.00 & 0.36 \\
Glucosamine & 0.12 & 0.16 & 0.19 & 0.70 & 0.20 & 0.83 & 1.73 & 1.65 & 0.03 & 0.00
\end{tabular}

Table 7 Comparison of carbohydrate average \% sample weight for three sources of castor seeds prepared using four methods. The castor seed sources for each preparation are indicated with single letter codes: Onalee (O), Whatcom (W) and PNNL (P).

Most notable in the carbohydrate data is a sharply diminished total arabinose concentration between the CM and AE (above 1.5\% wt) and the AP and ESP $(\leq 1 \% \mathrm{wt}$ ) samples. In the case of the ESP precipitated method, the \% weight of arabinose is $<0.5$. In general, the ratios of arabinose or xylose (found in hemicellulose) to mannose or $\mathrm{N}$ acetyl glucosamine (abundant in protein glycosylation) decreases following acetone precipitation. This indicates an enrichment of protein relative to cell wall carbohydrate with this preparation method. N-acetyl glucosamine is measured as "glucosamine" following acetylation as it is indistinguishable from native glucosamine. The ratio of arabinose to mannose is a discriminating feature as it is $>2$ in all preparations except the AP samples where it is $<1$. There is a similar reduction in the arabinose to glucosamine ratio from $>2$ to near 1 . The same trend appears to hold for the arabinose to myo-inositol where that ratio is $>2$ except for the AP sample where it is $<0.5$. The content of glucosamine is also significantly reduced (less than $0.05 \%$ weight) and the chiro-inositol undetectable in the ESP samples. In general all carbohydrates are drastically reduced in the ESP samples. 


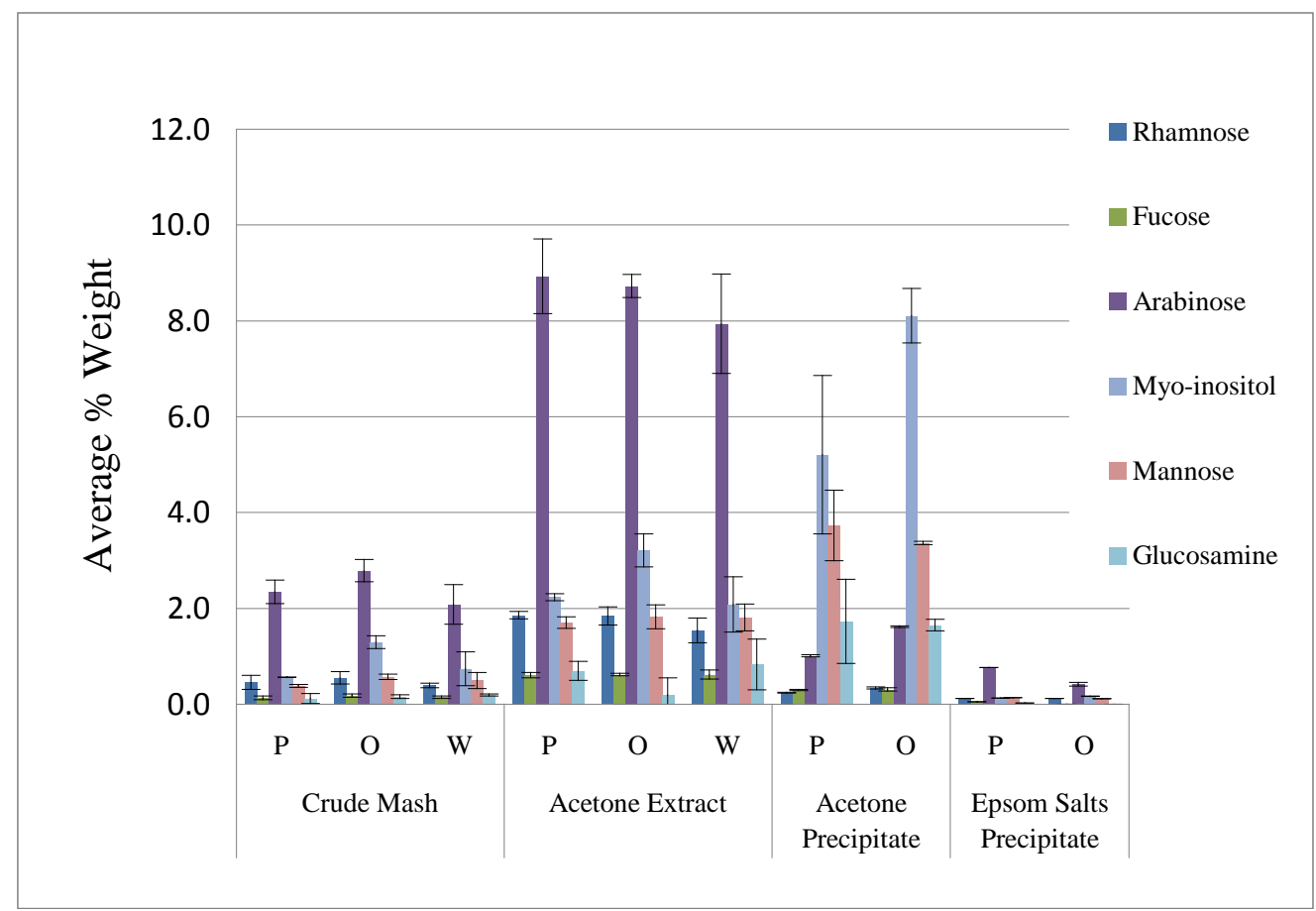

Figure 9 Comparison of four toxin preparations applied to three sources of castor seeds. Comparison of marker \% weight for four different methods for toxin preparation applied to different three sources of castor seeds, Onalee (O), Whatcom (W) and PNNL (P). For ease of interpretation, only six carbohydrates are included in this table. Standard deviation error bars included for each marker estimated from three analyses of each sample.

\section{Trimethylsilyl Carbohydrate Derivative Analysis}

Three issues became apparent during the development of a carbohydrate trimethylsilyation method. First, the changes in carbohydrate derivative also changed the chromatography such that previously well-resolved monosaccharides (as acetate derivatives) were co-eluting (ie: rhamnose and quinivose). Secondly, the efficiency of amino sugar derivatization was poor, necessitating exclusion of amino sugar markers from the data. Thirdly, the overall reproducibility of the method was lower than for the alditol acetate method. For these reasons, the method development was targeted toward creating suitable carbohydrate derivatives for isotope ratio mass measurements. Specifically, highly desirable compounds for IRMS analysis are: present after a wide variety of different toxin processing steps, not hydrolyzed out of a polymer, and require no reduction. The detected myo-inositol likely comes from two sources, phospholipids and galactinol disaccharides ${ }^{15}$. Inositol has a single potential exchangeable $\mathrm{O}$ during hydrolysis and no aldehyde group to reduce. Therefore the $\mathrm{O}$ content of this compound will likely be impacted the least by derivatization, making it the most suitable compound for ${ }^{18} \mathrm{O} /{ }^{16} \mathrm{O}$ measurement. This measurement is anticipated to provide complimentary data to the $\mathrm{D} / \mathrm{H}$ measurements for $\mathrm{MR}$.

The TMS derivatization procedure utilized the same hydrolysis and reduction steps as the AA procedure. The derivatization step required a simple reagent addition after drying, one hour incubation and then direct analysis of the mixture. The carbohydrate profile of 
the TMS derivatives was somewhat different then for the AA derivatives with myo and chiro-inositol eluting late. Compounds that are well-resolved chromatographically are most desirable for compound-specific GC-IRMS measurements. No isotope ratio data was collected using these derivatives, however, the SAM for performing this procedure is in place and available for future use.

\subsection{Integration of Data}

The fatty acid and carbohydrate abundance data can each be used to differentiate between samples prepared using different recipes and indicate the type of process used. Each data type provides complimentary information. A principle component analysis (PCA) was performed to determine which components provide the most discriminating information (figure 10). Abundance data for MR and all eighteen carbohydrates was used in this analysis.

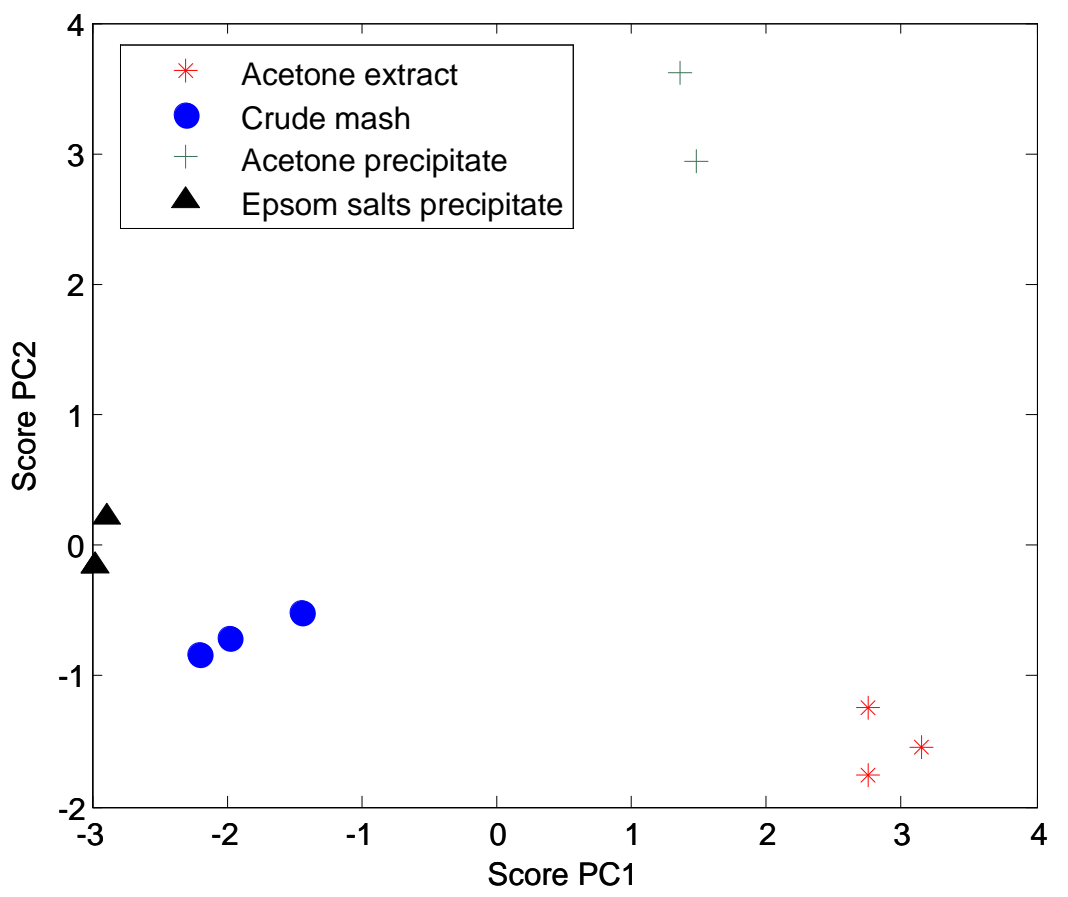

Figure 10. Principal component scores plot for the four toxin preparation types. The replicate analysis for each preparation type and seed source was combined into a single data point.

The discriminating variables used to create the plot were rhamnose, fucose, arabinose, xylose, methyl ricinoleate. The data demonstrate a clear grouping according to preparation type using these components. 


\subsection{Conclusions}

\section{1 $\quad$ Fatty Acid Analysis}

One goal for this work was to demonstrate indicators of intentional processing of toxin samples. Residual castor oil was measured using the major constituent MR as a proxy. Reduced MR abundance clearly distinguished between the samples of castor seed mash and other preparation types. This distinction is important because the common steps for intentionally preparing castor samples are seed hull and oil removal.

We observed some variability in MR abundance within a preparation type. The sources of that variability may reflect heterogeneity of the sample or analyte solubility in the extraction or analysis solvents. Further refinement of the method will include changing the extraction solvent to more closely match the solvent used for analysis. However, a clear decrease in MR abundance could be seen after toxin extraction. These data suggest that MR abundance within an unknown sample can distinguish between crushed castor seeds and seeds that were manipulated to remove seed components.

An advantage of this procedure is that identical samples can be analyzed for the MR D/H isotope ratio. The isotope ratio information can be used to distinguish samples from seeds grown using isotopically distinct water, which, due to meteorological trends and physical isotope fractionation, is frequently observed in different geographic regions. Extensive previous work has demonstrated that $\mathrm{D} / \mathrm{H}$ ratios of castor oil from different regions are distinguishable ${ }^{21}$. D/H ratios can be used to further distinguish samples, but a lack of difference will not necessarily indicate the identical seed source. The possibility of overlapping isotope ratio in different regions cannot be excluded.

We sought to demonstrate indicators of intentional processing of toxin samples. A clear decrease in MR abundance could be seen after the initiation of four preparation techniques that parallel available toxin extraction methods. MR abundance within an unknown sample can help distinguish between crushed castor seeds and seeds that were manipulated to remove seed components, specifically lipid components.

\subsection{Carbohydrate Analysis}

A method for liberating, derivatizing and detecting carbohydrate monosaccharides was applied to the toxin preparations. The carbohydrates of particular interest where those known to be abundant in specific seed components. Arabinose and xylose present in cell wall hemicellulose was expected to decrease while mannose and glucosamine abundant in protein glycosylation was anticipated to increase with increasingly pure protein toxin preparations.

Derivatized carbohydrate monomers could also be used for stable isotope ratio measurements similar to the work demonstrated for MR. Unlike MR, the targeted measurement would be on ${ }^{18} \mathrm{O} /{ }^{16} \mathrm{O}$ for the carbohydrates. This measurement would 
necessitate a suitable derivatization method to make volatile compounds without significantly altering the native $\mathrm{O}$ composition of the carbohydrate. For this reason we produced a method for forming trimethylsilyl derivatives, which is available for application to this work.

The carbohydrate abundance data show a general increase in the abundance of all carbohydrates following AE, indicating an increase in the amount of carbohydrate relative to the total sample weight once the oil is removed. The protein precipitation methods were expected to enrich the protein content of the sample relative to starch and cell wall carbohydrates. This was clearly observed in the AP samples with a relative decrease in the arabinose from hemicellulose and increase in mannose and glucosamine content, abundant in protein glycosylation. The ESP method looked distinct from all preparation types sample with a marked decrease in the content of all carbohydrates, particularly a loss of chiro inositol. This likely reflects the poor yield in general for this toxin preparation method. All toxin preparation methods were distinct from one another and could be determined by either the measured percent weight of specific carbohydrates, the ratios between these carbohydrates, or both.

\subsection{Data integration}

The data on fatty acid and carbohydrate abundance can each be used to differentiate between and indicate the type of process used for toxin production. Importantly each type of data is complimentary in that the amount of MR is dramatically different between CM samples and all other types of preparations, whereas additional dramatic differences can be seen between $\mathrm{AE}$ and the protein precipitate toxin preparations using carbohydrate abundance.

Using PCA as an exploratory tool, the two types of data appear to easily discriminate between each toxin sample type. This approach also confirmed several differentiating changes that visually appeared to separate one sample preparation type from another. Additional tools can be applied to more confidently identify the preparation method. However this demonstration illustrates the utility of integrating more than one type of data.

\subsection{Path Forward}

This report focused on using both carbohydrate and fatty acid abundance data to determine the type of process used for manipulating castor beans to produce toxin extracts. Additional methods testing to determine robustness is needed. Factors to be addressed include: preparing toxin from seeds with variable oil content, including additional methods of toxin preparation, evaluating the minimum sample requirements, defining the data criteria for identification of toxin preparations and updating the standard analytical methods as appropriate. These issues are the subject of further research within the DHS S\&T chemical forensics program. 


\subsection{References}

(1) Lundger, S., L Melin, C Nilsson, P von Shoenberg. : Umea, SE, 2004.

(2) Amukele, T. K.; Roday, S.; Schramm, V. L. Biochemistry 2005, 44, 4416-4425.

(3) 42 ed.; Services, D. o. H. a. H., Ed.: Washington, DC, 2002; Vol. vol 240, pp Part 1003.

(4) In Biosafety in Microbiological and Biomedical Laboratories Handbook; Millard., E. C. B., Ed., 2005; Vol. 5th edition, pp pp 1-14.

(5) Kamimura R, S. V., Final Report ed.; Lawrence Livermore National Laboratory.: Livermore, CA, 2005.

(6) Weiss, E. A. Oilseed crops; Longman: London and New York, 1983.

(7) Ogunniyi, D. S. Bioresource Technology 2006, 97, 1086-1091.

(8) InfernoMDM.; Temple of the Screaming Electron (TOTSE) 2004; Vol. 2004.

(9) Harber, D. In Assorted Nasties; Desert Publications: El Dorado, AR 71731, 1993.

(10) Simmons, B., JH Russell Analytical Biochemistry 1984, 146, 206-210.

(11) Saxon, K. The Poor Man's James Bond; Desert Publications: El Dorado, AR 71730, 1991.

(12) Preisler, S. In Silent Death; Festering Publications: Green Bay, WI 54301, 1997; Vol. Chapter 10.

(13) Craig, H., OH Alderks, AH Germin, SH Dieke, CL Karel. : USA, 1952.

(14) Naughton, F. C. In Kirk-Othmer Encyclopedia of Chemical Technology., Fifth Edition ed.; John Wiley \& Sons, Inc., 1993, pp 1-17.

(15) Horobowicz, M. a. R. O. Seed. Sci. Res. 1994, 4, 385-405.

(16) Esteves, B.; Graca, J.; Pereira, H. Holzforschung 2008, 62, 344-351.

(17) Fox, A.; Black, G. E.; Fox, K.; Rostovtseva, S. Journal of Clinical Microbiology 1993, 31, 887894.

(18) Wunschel, D.; Fox, K. F.; Black, G. E.; Fox, A. Systematic and Applied Microbiology 1994, 17, 625-635.

(19) Ehleringer, J. R., Kreuzer-Martin, H.W., West, J.B., Lowe, T.M., Barnette, J.E., and Hoffman, J. ; FBI report BAA-0034104: Salt Lake City UT, 2006.

(20) West, J. B., Kreuzer-Martin Helen W, Ehleringer, James R. In Isoscapes: Understanding movement, pattern, and process on Earth through isotope mapping; West, J. B., Bowen, G.J. Dawson, T.E. Tu, K.P., Ed.; Springer Science + Business Media B.V, 2010, pp 168-178.

(21) A, F.; L, M. S.; J, G., Eds. Preparation of alditol acetates and their analysis by gas chromatography and mass spectrometry. ; CRC Press: FL, 1989.

(22) Wunschel, D. S.; Colburn, H. A.; Fox, A.; Fox, K. F.; Harley, W. M.; Wahl, J. H.; Wahl, K. L. Journal of Microbiological Methods 2008, 74, 57-63.

(23) Adams, M. A.; Chen, Z. L.; Landman, P.; Colmer, T. D. Analytical Biochemistry 1999, 266, 7784.

(24) Rojas-Escudero, E.; Alarcon-Jimenez, A. L.; Elizalde-Galvan, P.; Rojo-Callejas, F. Journal of Chromatography A 2004, 1027, 117-120.

(25) Company, P. C. 1995, 0322, 1-7.

(26) Pierce Product Information 1995, 0322, 1-7. 


\subsection{Appendix A}

\section{PNNL Castor Bean Preparation Methods}

\section{1) Inactivation of Intact Seeds}

Bake castor seeds for 30 minutes at $100{ }^{\circ} \mathrm{C}$. A GC oven works fine for this step. The toxin is now considered inactive, so that any "ricin" preparations using baked seeds do not need to be entered into the active toxin inventory. The seeds and any extract prepared from them still must be put in the burn barrel for disposal.

\section{2) Toxin Preparation from Inactivated Seeds}

a) Preparation of ground beans as Castor seed mash (CM) Method. (Adapted from Saxon, K 1991).

(1) Note: This is the first preparation method used. However, additional preparation methods used in the study will use the ground beans from this method as starting material for additional steps used in methods 2A, 2B, and 2C below.

(2) Description

(a) Weigh 2 grams of castor beans and place in a $100 \mathrm{ml}$ beaker

(b) Add $50 \mathrm{ml}$ or cover beans with $3 \mathrm{~N} \mathrm{Na} \mathrm{OH}$ and let soak 1 hour to overnight with smaller beaker placed on top of beans to keep them immersed in solution (I have soaked them for up to $2 \mathrm{hr}$ with no observable difference.) Decant the $\mathrm{NaOH}$ into a container for re-use. It will have turned brown.

(c) Rinse the beans with cold water. Pat them dry or air-dry them.

(d) To remove the husk, place a bean in a weigh boat and use forceps and/or a small weighing spatula to pierce the husk and peel it from the bean. The peeled bean should be white. It if it is very discolored, do not use it. If the beans are active, put the husk fragments into the solids kill container in the BSC and treat them with $10 \%$ bleach.

(e) Move the peeled beans to a clean weigh boat. Cover them with a piece of weighing paper and crush them thoroughly by grinding a pestle against the paper (to keep the bean material off the pestle).

(f) Transfer the bean mash to a container for storage or processing.

b) Acetone Extraction (AE) Method (Adapted from Preisler, S. 1997 and InfernoMDM 2004).

(1) Transfer the ground beans (from 2f) to either a $40 \mathrm{~mL}$ I-CHEM vial (small amounts) or beaker (larger amounts).

(a) For every gram of beans you started with, add $\sim 4$ g solvent to the container.

(b) Example: add mash to a $10 \mathrm{ml}$ beaker and cover with $5 \mathrm{ml}$ of acetone 
(2) Put in a stir bar and close the vial tightly. If you are using an Erlenmeyer flask, cover it with foil and then seal it with Parafilm.

(3) Stir mixture for 1 to 2 hours

(a) Decant acetone and repeat 2 hour soak with a fresh $5 \mathrm{ml}$ volume

(b) Decant acetone supernatant a soak a third time with fresh $5 \mathrm{ml}$ acetone overnight.

(4) Pour the mixture through a coffee filter, using additional solvent to rinse the container.

(5) When the solvent has dripped through, spread the filter out to dry.

(6) When the filter is dry, scrape the powder off the filter and transfer it to a vial. The usual dry time for volatiles measurement is $24 \mathrm{~h}$.

\section{c) Epsom Salt Precipitation (ESP) Method (Adapted From Ehleringer, J.R et al. 2006 and Harber, D. 1993).}

(1) Transfer the peeled beans (from 2d) to weigh paper. Fold weigh paper in half and place in between newspaper. Pulverize the seeds, using a hammer, pestle, or other tool.

(2) Using a spatula, scrape the seeds onto a paper towel in a thin line ( $<0.5$ in wide). Fold paper towels over at least four times and fold into another paper towel.

(3) Place six bricks on top of the paper towels. Check paper towels two to four hours later. I use heavy catalogs and large bottles of solutions.

(4) If oil is showing through the paper towel, replace with new paper towels. Let sit overnight.

(5) Using a spatula, scrape seeds off paper and place into mortar.

(6) Grind seeds with pestle and scrape into $25 \mathrm{ml}$ Erlenmeyer (ER) flask. I have also used the hand blender to blend seeds with salt water.

(7) Mix $0.8875 \mathrm{~g}$ of $\mathrm{NaCl}$ with $8.75 \mathrm{ml}$ of water.

(8) Add salt solution to $25 \mathrm{ml}$ ER flask containing pulverized seeds.

(9) Cover with parafilm. Let sit for 48 hours. Occasionally stir solution. (There should be foam on top of the water formed by the mash.)

(10) Filter mash mixture through two coffee filters. Squeeze all water out of the coffee filters. 12. Mix $1.25 \mathrm{ml}$ of Epsom salt into $22.5 \mathrm{ml}$ of water.

(11) Add Epsom salt solution to NaCl-protein solution.

(12) Stir and let sit for $1 / 2$ hour. Precipitate should fall out of solution.

(13) Stir and let sit for another hour.

(14) Pour precipitate and solution into test tubes. (Cannot use coffee filters pores are too large). 17. Spin test tubes at level 6 for 30 seconds and decant cloudy water. (Precipitate should be a pellet at the bottom of the test tube.)

(15) Decant solution and wash pellet three times with $25 \mathrm{~mL}$ of $18 \mathrm{M} \Omega \mathrm{H} 20$, centrifuging for 20 minutes between each wash to preserve pellet.

(16) Once test tubes are dry, scrape protein precipitate onto weigh paper (or a small weigh boat) Pre-weigh labeled vial and transfer protein precipitate into vial. Weigh vial to get total grams of protein precipitate.

\section{d) Acetone Protein Precipitation (AP) Method (Received from Vass, A. 2008)}


(1) Transfer the dehulled seeds (from 2d) to a small beaker.

(2) Using a small blender or tissue grinder, grind shelled seeds with Phosphate Buffer Solution (PBS).

(a) Use $4 \mathrm{X}$ volume of buffer to weight of seeds.

(b) For a $4 \mathrm{~g}$ of seeds use $16 \mathrm{~mL}$ of PBS

(3) Centrifuge at $4^{\circ} \mathrm{C}$ for $\sim 20 \mathrm{~min}$ at $10 \mathrm{~K} \mathrm{x} \mathrm{g.}$

(a) This will produce three layers (debris at the bottom, middle aqueous and oil at the top). Most of proteins, including ricin, accumulate in the middle aqueous layer.

(4) Puncture the top oil layer and recover the aqueous portion. (This step is the deoiling process). Repeat the centrifugation process, if necessary.

(5) Take the aqueous layer from step and add acetone (vortex briefly after each addition of acetone) until a precipitate forms, typically a $90 \%$ final acetone solution.

(a) This step is temperature susceptible, so perform this in ice bath or at cold temperatures.

(6) Centrifuge at $10 \mathrm{~K} \mathrm{x} \mathrm{g} \mathrm{for} 20 \mathrm{~min}$. Collect precipitate and discard supernatant. Dry the precipitate in air or under flowing nitrogen.

\section{3) References}

a) Saxon, Kurt. 1991. In: The Poor Man's James Bond. Vol. 1. Desert Publications, El Dorado, AR 71730, ISBN number 0-87947-230-8.

b) InfernoMDM. “How to make Ricin”.Temple of the Screaming Electron (TOTSE) website: http//www.Totes.com/en/bad_ideas /irresponsible_activities/163208.html. Content captured January 24, 2004.

c) Preisler, Steve. Chapter 10, Ricin: Kitchen Improvised Devastation. In Silent Death. Festering Publications, Green Bay, WI 54301. 1997. ISBN 1-55950-159-6]

d) Ehleringer, J.R., Kreuzer-Martin, H.W., West, J.B., Lowe, T.M., Barnette, J.E., and Hoffman, J. 2006. Stable Isotope Ratio Analyses of Castor Bean: A Ricin Signature Program. FBI report BAA-0034104.

e) Harber, David. 1993. In: Assorted Nasties. Desert Publications, El Dorado, AR 71731 ISBN number 0-87947-231-6)

f) Vass, A. 2008. Personal communication. Performed at Oak Ridge National Laboratory in collaboration with Ehleringer et al. 


\subsection{Appendix B}

\begin{tabular}{|l|l|}
\hline DHS Chemical Forensics Program & Procedure \#: PNNL-FAME-063009 \\
\cline { 2 - 3 } STANDARD ANALYTICAL METHOD & Date of Issue: June 30, 2009 Page 32 of \\
\cline { 2 - 3 } & Revision \#: 1 \\
\hline Title: Preparation and Analysis of Fatty Acid Methyl Ester \\
Derivatives from Castor Samples
\end{tabular}

Prepared by: Helen Kreuzer* and James Moran

*Contact information: PO Box 999 MS P7-50, Richland WA, 99354.

Helen.Kreuzer@pnl.gov; (509) 376-3885

Prepared at: Pacific Northwest National Laboratory, Richland WA.

Introductory Notes/Comments: This SOP describes the preparation of fatty acid methyl ester (FAME) samples from processed and un-processed castor bean mash.

Castor seeds are approximately 50\% castor oil by weight, and approximately $90 \%$ of the fatty acid content of castor oil is ricinoleic acid, 12-hydroxy-9-cis-octadecenoic acid. Ricinoleic acid had only been found in castor seeds and ergot. Methods for processing castor seeds to extract ricin typically begin with one of several oil extraction procedures that remove the majority of the ricinoleic acid, and thus processed castor seed mash has a different fatty acid profile from un-processed mash. The FAMEs prepared according to this SOP can be analyzed by standard GC-MS to confirm the identity of the fatty acids, and by GC-IRMS to determine their isotope ratios.

Preparation of fatty acid samples must be carried out using scrupulously clean glassware and metal tools from which all organic residue has been removed. Equipment can be de-greased either by baking for 5 hours at $500{ }^{\circ} \mathrm{C}$ in a muffle furnace (to ash all organics), or by extensive rinsing with a series of solvents of decreasing polarity: methanol, chloroform, and hexanes. Because of these requirements, plasticware cannot be used. Test tube and vial lids must be lined with polytetrafluoroethylene (PTFE, Teflon), and must be solvent-rinsed before use. Volumetric measurements can be made by introducing the liquid into an ashed graduated cylinder, and using an ashed Pasteur pipette to remove the desired volume. Solutions must also be grease-free, and are prepared by extracting them with hexane a minimum of 3 times before use. Solvents must be of the highest grade of purity. Great care must be taken not to introduce fingerprints to any equipment or solution, as fingerprints contain oils with many of the same fatty acids as those found in castor beans (though not ricinoleic acid). All ashed and solvent-rinsed equipment should be kept segregated from common stocks of laboratory supplies to avoid inadvertent contamination.

\section{1) SCOPE AND APPLICATION:}

Castor seeds are approximately 50\% castor oil by weight, and approximately $90 \%$ of the fatty acid content of castor oil is ricinoleic acid, 12-hydroxy-9-cis-octadecenoic acid. Ricinoleic acid had only been found in castor beans and ergot. Methods for processing castor beans to extract ricin typically begin with 
one of several oil extraction procedures that remove the majority of the ricinoleic acid, and thus processed castor seed mash has a different fatty acid profile from un-processed mash. Analysis of the fatty acid content of a sample can therefore reveal whether the sample underwent a de-oiling procedure. This document describes a method for preparing fatty acids from castor seed samples and derivitizing them as methyl esters, which renders them volatile. Fatty acid profiles of the samples can then be obtained by gas chromatography.

\section{2) SUMMARY OF METHOD:}

This procedure begins with a saponification step, a 2 hour incubation of the sample in $0.5 \mathrm{M} \mathrm{NaOH}$ at $70^{\circ} \mathrm{C}$. This treatment cleaves ester bonds and liberates fatty acids (in their ionic form) from lipids, lipoproteins, and lipopolysaccharide. Since ricin can be inactivated by exposure to $0.06 \mathrm{~N} \mathrm{NaOH}$ for 30 minutes at room temperature, this treatment also inactivates any ricin that might be present in the sample.

Following saponification, the solutions are acidified, and the re-protonated fatty acids are extracted into methyl-t-butyl ether (MTBE). The MTBE is evaporated under nitrogen, and when the solution reaches a small volume, it is transferred into a fresh vial for the methylation reaction. At this point, samples may be stored in the freezer overnight.

The remaining MTBE is evaporated, and the samples are resuspended in 3\%BF3 in methanol. The vials are sealed and incubated at $100^{\circ} \mathrm{C}$ for $2 \mathrm{~h}$ to methylate the fatty acids. This step must be anhydrous, as water hydrolyzes the esters. Therefore, anhydrous methanol must be used and great care taken to avoid contaminating the samples with water.

Following methylation, the FAMEs are extracted into hexane and the final volume decreased to $\sim 100 \mu \mathrm{L}$ by evaporation under nitrogen.

The solution of FAMEs can be analyzed by standard GC-MS, by GC-FID, or by GC-IRMS.

\section{3) INTERFERENCES:}

a) Samples can be contaminated by grease from fingerprints or any other source. All equipment and solutions must be rendered grease-free prior to use, and should be protected from inadvertent contamination.

b) Preparation of fatty acid samples must be carried out using scrupulously clean glassware and metal tools from which all organic residue has been removed. Equipment can be de-greased either by baking for 5 hours at $500{ }^{\circ} \mathrm{C}$ in a muffle furnace (to ash all organics), or by extensive rinsing with a series of solvents of decreasing polarity: methanol, chloroform, and hexanes.

c) Because of these requirements, plasticware cannot be used. Test tube and vial lids must be lined with polytetrafluoroethylene (PTFE, Teflon), and must be solvent-rinsed before use.

d) Volumetric measurements can be made by introducing the liquid into an ashed graduated cylinder, and using an ashed Pasteur pipet to remove the desired volume. Solutions must also be grease-free, and are prepared by extracting them with hexane a minimum of 3 times before use.

e) Solvents must be of the highest grade of purity. Great care must be taken not to introduce fingerprints to any equipment or solution, as fingerprints contain oils with many of the same fatty acids as those found in castor beans (though not ricinoleic acid).

f) All ashed and solvent-rinsed equipment should be kept segregated from common stocks of laboratory supplies to avoid inadvertent contamination.

\section{4) SAFETY:}


a) Samples could contain active ricin. The saponification step will inactivate any toxin that might be present, but equipment that touches the sample prior to saponification (for example, to weigh it) should be decontaminated appropriately if it might contain active toxin.

b) $\mathrm{NaOH}$ is corrosive. Eye protection should be worn when working around or with the sponification vials.

c) Hexane, methanol, and MTBE are flammable solvents.

\section{5) APPARATUS:}

a) Pierce Reacti-Therm heating unit with T-2 sample block containing 16mm-diameter holes

b) Pierce Reacti-Vap gas manifold attached to the heating unit and plumbed to a tank of nitrogen

c) Clinical centrifuge with rotor that holds $16 \mathrm{~mm}$-diameter tubes

6) REAGENTS AND MATERIALS: All solvents should be of highest purity. All solutions must be extracted a minimum of 3 times with hexane prior to use. Solutions must be stored in ashed glass containers with ground-glass stoppers All glassware must be covered with aluminum foil and baked at $500{ }^{\circ} \mathrm{C}$ for 5 hours prior to use. Vial and test tube lids must be lined with PTFE and solventrinsed (3 times with methanol, 3 times with chloroform or dichloromethane, and 3 times with hexane) priot to use. Materials for FAME preps should be kept segregated from common laboratory supplies to prevent inadvertent contamination.
a) $16 \times 125 \mathrm{~mm}$ screw-cap test tubes with PTFE-lined caps
b) $16 \times 50 \mathrm{~mm}$ vials with PTFE-lined caps
c) Pasteur pipets
d) Aluminum foil
e) $3 / 4$ inch Teflon tape ( $1 / 2$ inch will work, but $3 / 4$ is easier to manipulate)
f) Hexane
g) Chloroform or dichloromethane
h) Methanol, chromatography grade
i) Methyl ricinoleate, (99\%, Sigma-Aldrich-Fluka [83916])
j) Ricinoleic acid ( 99\% Sigma [R7257])
k) Palmitic acid methyl ester (Government Scientific Source, Inc. P5177-5G)
l) Methanol, anhydrous with molecular sieves (for methylation reaction)
m) Methyl-tert-butyl ether
n) $0.5 \mathrm{M} \mathrm{NaOH}$
o) $\sim 4 \mathrm{M} \mathrm{HCl}$
p) $5 \% \mathrm{NaCl}$

\section{7) SAMPLE COLLECTION, PRESERVATION AND HANDLING:}

a) This SOP assumes that samples of processed or un-processed castor bean mash will be provided to the preparer.

b) Samples are kept in a cool dry environment prior to analysis to prevent microbial growth and sample breakdown. Handling of samples requires caution (see section 4. Safety).

c) Manipulation of the sample requires methanol rinsed spatulas or other metal devices.

d) For highly hydrostatic samples, limited air flow during manipulation is required

\section{8) STANDARDS AND CONTROLS:}

a) Prior to preparing any samples, procedure blanks should be run using all materials and reagents to make certain that all are grease-free.

b) An external standard of Ricinoleic acid can be included in the derivatization process to assess process variation. 
c) Methyl ricinoleate and Palmitic acid methyl ester (10:1 ratio) are injected at the start and end of the batch of samples

\section{9) CALIBRATION:}

a) Five concentrations of methyl ricinoleate can be included in the autosampler run to provide relative quantities of that marker in the sample(s).

b) The standards should be run both before and after the samples with unknown concentrations of the marker to confirm

10) SAMPLING:

a) $20 \mathrm{mg}$ of solid sample material is weighed out and placed into $5 \mathrm{~mL}$ hydrolysis tubes for processing. A blocked and randomized scheme is used for sample analysis including solvent blanks and external standards mixtures.

\section{1) OTHER QUALITY ASSURANCE CONSIDERATIONS:}

a) A mixture of methyl ricinoleate and palmitic acid methyl ester standard solution is injected and analyzed on the GC (10ng :1 ng injected respectively) with each sample set to confirm the retention time for that compound and provide a relative quantitation.

\section{2) PROCEDURE (Step-by-Step Directions)}

a) Weigh out $20 \pm 1 \mathrm{mg}$ sample, using a solvent-rinsed spatula and glassine paper that has been handled only with gloved hands. Transfer the sample to an ashed 16 x $125 \mathrm{~mm}$ test tube.

b) Add $5 \mathrm{~mL}$ grease-free $\mathrm{NaOH}$. Cap tightly with PTFE-lined, solvent-rinsed cap and incubate $2 \mathrm{~h}$ at $70^{\circ} \mathrm{C}$ in Pierce Reacti-Therm heating block.

c) Cool sample to room temperature and lower $\mathrm{pH}$ to $2-6$ using $\sim 4 \mathrm{M}$ grease-free HCl. Add $2.5 \mathrm{~mL}$ $5 \% \mathrm{NaCl}$ and $5 \mathrm{~mL} \mathrm{MTBE}$. Extract and transfer the organic layer to a fresh ashed $16 \mathrm{x} 125 \mathrm{~mm}$ test tube.

d) Extract twice more with $5 \mathrm{~mL}$ MTBE, combining the organic layers.

e) Evaporate most of the MTBE under a stream of nitrogen. When the volume of the sample is about $3 \mathrm{~mL}$, transfer it to an ashed $16 \mathrm{~mm}$ x 50mm vial. Cap with PTFE-lined lid and store overnight in the freezer.

f) Evaporate the rest of the MTBE from the samples in the vials. Add $1 \mathrm{~mL} \sim 3 \%$ BF3 in anhydrous methanol. Cap tightly, seal with Teflon tape, winding in the direction to tighten the cap.

g) Incubate for $2 \mathrm{~h}$ at $100^{\circ} \mathrm{C}$ in the Pierce Reacti-Therm heating block.

h) Cool to room temperature. Transfer the reaction mixture to a fresh ashed 16 x $125 \mathrm{~mm}$ test tube. Rinse the sample vial 3 times with $\sim 0.5 \mathrm{~mL}$ methanol, then 3 times with $\sim 0.5 \mathrm{~mL}$ hexane, adding the rinsings to the test tube.

i) Add $2 \mathrm{~mL} \mathrm{5 \%} \mathrm{NaCl}$ and $3 \mathrm{~mL}$ hexane to the sample. Extract and remove the hexane layer to a fresh ashed $16 \times 125 \mathrm{~mm}$ test tube.

j) Extract twice more with $3 \mathrm{~mL}$ hexane, combining organic layers. 
k) Evaporate the hexane to a very small volume under nitrogen. When the volume is small enough $(\sim 200 \mu \mathrm{L})$, transfer the sample to a GC vial insert in a standard GC vial. Continue evaporating to a very small volume. Rinse the test tube 3 times with $\sim 200 \mu \mathrm{L}$ hexane, adding each rinsing to the GC vial insert when the volume in the insert becomes small enough to do so.

l) After adding the third rinsing to the GC vial insert, evaporate the volume to approximately 100 $\mu \mathrm{L}$. Cap the $\mathrm{GC}$ vial tightly and store the sample at $4{ }^{\circ} \mathrm{C}$.

m) Samples can be analyzed by standard GC-MS, by GC-FID, or by GC-IRMS. An example set of GC-MS Analysis parameters is given.

i) CTC Pal Autosampler with 10uL liquid syringe

Air Volume: 1uL Pre-clean with Solvent $15 x$ (Solvent 1 is methanol) Pre-clean with Solvent 2 5x (Solvent 2 is chloroform)

Sample Fill: $1 \mathrm{uL}$

Filling speed: $5 \mathrm{uL} / \mathrm{s}$

Filling strokes: 5

Inject to split/splitless inlet

Injection speed: $7 \mathrm{uL} / \mathrm{s}$

Pre Inject delay: 0ms

Post inject delay: $0 \mathrm{~ms}$

Post clean with solvent $1: 5 \mathrm{x}$

Post clean with solvent 2: $5 \mathrm{x}$

Pullup delay: $1.0 \mathrm{~s}$

\section{ii) GC Parameters}

(1) Oven

$110^{\circ} \mathrm{C}$ for $2 \mathrm{~min}$

$10^{\circ} \mathrm{C} / \mathrm{min}$ to $150^{\circ} \mathrm{C}$

$2^{\circ} \mathrm{C} / \mathrm{min}$ to $240^{\circ} \mathrm{C}$

$15^{\circ} \mathrm{C} / \mathrm{min}$ to $320^{\circ} \mathrm{C}$ hold for $10 \mathrm{~min}$

Run Time $66.33 \mathrm{~min}$.

(2) Split/Splitless inlet:

He carrier

Run in splitless mode with a surge

Heater on, $300^{\circ} \mathrm{C}$

Constant septum purge flow

Split ratio: 7:1

Split flow: $11 \mathrm{~mL} / \mathrm{min}$

Splitless time: $1.0 \mathrm{~min}$

Surge pressure: $0.5 \mathrm{psi}$

Surge duration: $0.20 \mathrm{~min}$

(3) Column 
Restek RTX 1MS: 60m x 250 um x 0.25 um

Constant flow, $1.5 \mathrm{~mL} / \mathrm{min}$

iii) Flame Ionization Detector

Base temperature: $300^{\circ} \mathrm{C}$

Air flow: $350 \mathrm{~mL} / \mathrm{min}$

H2 flow: $35 \mathrm{~mL} / \mathrm{min}$

Make up helium: $35 \mathrm{~mL} / \mathrm{min}$

\section{3) METHOD PERFORMANCE:}

a) The method performance is evaluated by the inclusion of water blank samples with each derivatization batch to ensure that no extraneous peaks from the process are present that may overlap with castor marker peaks

b) Up to three replicate samples are included to estimate the standard deviation of the peak area measurement

c) The purchased methyl ricinoleate as well as methyl palmitate are included in the GC run both before and after samples to monitor for detector drift in estimations of quantity for each marker.

\section{4) REFERENCES}

a) Kreuzer-Martin, H.W., M.J. Lott, J.R. Ehleringer, and E.L.Hegg. Metabolic processes account for the majority of the intracellular water in log-phase Escherichia coli cells as revealed by hydrogen isotopes. Biochemistry 45: 13622-13630, 2006.

b) Wakeham, S.G., and T.K. Pease. Lipid Analysis in Marine Particle and Sediment Samples: A Laboratory Handbook. Skidaway Institute of Oceanography, Savannah, GA, 2004. 


\subsection{Appendix C}

\begin{tabular}{|l|l|}
\hline DHS Chemical Forensics Program & Procedure \#: PNNLCHO-AA-063009 \\
\cline { 2 - 2 } STANDARD ANALYTICAL METHOD & Date of Issue: June 30, 2009 Page 38 of \\
\cline { 2 - 2 } & Revision \#: 1 \\
& 57 \\
\hline Title: Preparation and Analysis of Alditol Acetate \\
Carbohydrate Derivatives from Castor Samples \\
\hline
\end{tabular}

Prepared by: David S. Wunschel* PhD, Kate Antolick, and Heather Colburn Ph. D.

*Contact Information: PO Box 999 MS P8-13, Richland WA, 99354.

David.Wunschel@pnl.gov; (509) 372-2951

Prepared at: Pacific Northwest National Laboratory, Richland WA.

\section{Introductory Notes/Comments:}

This method is written to create alditol acetate (AA) derivatives from carbohydrates found in forensic ricin samples. It is written as a partner method to two other methods for derivatization and analysis of carbohydrates as trimethylsilyl (PNNLCHO-TMS-063009) and fatty acids as methyl esters (PNNLFAME-063009). The method is constructed from previous experience with a method for analysis of bacterial sugars as alditol acetates ${ }^{18,22}$. This method has been proven to be robust for detecting and profiling neutral and amino sugars from complex biological samples ${ }^{19,23}$.

The acquisition of instrument data on the identity, abundance and isotope ratio of these compounds will utilize a gas chromatograph mass spectrometer (GC-MS) for obtaining marker identity and relative abundance.

Care is required in the maintenance of laboratory equipment and supplies to prevent introduction of extraneous compounds and carryover between samples. Steps are required, such as cleaning vacuum manifolds used for solid phase extraction (SPE) sample cleanup, acid washing of glassware (particularly hydrolysis tubes) and chloroform rinsing of all glassware such as pipettes and reaction vials that touch the final derivatized sugars.

This method is described with a preliminary description of its performance. The method will be evaluated and more completely defined performance criteria established after testing against a standard set of samples in FY09. 


\section{1) SCOPE AND APPLICATION:}

This method focuses on analysis of samples containing the plant toxin ricin, which is derived from castor seeds (R. communis). Approximately $25 \%$ of the castor seed mash is carbohydrate. The method focuses on preparation of solid samples for carbohydrate analysis by GC-MS. The data produced by GC-MS will be a relative quantitation (percent dry weight) of monomeric carbohydrates derived in the sample following hydrolysis reduction and derivatization of the neutral and amino monosaccharides. A preliminary evaluation of the performance criteria will be given, but is subject to the method testing in the FY09

\section{2) SUMMARY OF METHOD:}

a) This method relies on first liberating any sugar monomers (e.g. glucose, inositol, arabinose, mannose, etc.) from any oligomeric or polymeric structures that they may be bound in using acid hydrolysis. Examples of target compounds are the glucose-rich starch, inositol of phospholipids and "cyclitol" disaccharides, xylose/ arabinose rich hemicellulose polymers within the cell wall and the mannose rich protein glycosylation.

b) Following acid hydrolysis, the samples are neutralized using an organic base and hydrophobic contaminants are removed by solid phase extraction. The aldose and ketose (C-1 carbonyl containing) sugars are then reduced to their alditol form using sodium borodeuteride. The use of the borodeuteride adds a deuterium to the C-1 carbon, allowing native aldoses and ketose carbohydrates to be distinguished from native alditols in the mass spectrum (glucose is distinguishable from glucitol). The presence of C-1 containing fragment masses that are $1 \mathrm{~m} / \mathrm{z}$ larger for aldoses (e.g. glucose) than those found for native alcohol sugars (e.g. glucitol).

c) Following reduction, the residual borodeuteride is removed by addition of methanol-acetic acid addition to dry it away as tetra methyl borate gas. The result is residual sodium and acetate. Derivatization of the reduced sugars can then take place by addition of acetic anhydride to form acetate derivatives which are volatile enough for GC-MS analysis.

d) Following derivatization there are steps to remove residual acetic anhydride and any remaining hydrophilic contaminants and are ready for analysis by GC-MS. This method can detect a wide range of neutral and amino carbohydrate markers from as little as $20 \mathrm{mg}$ of sample.

e) This method was not developed with the analysis of acidic sugars in mind, although further alterations may make that possible in the future. The derivatives are anticipated to be stable at $4^{\circ} \mathrm{C}$ for up to a month for reanalysis.

\section{3) INTERFERENCES:}

a) The method relies on having clean, solvent rinsed glassware for preparation of the derivatives.

b) The presence of water in the sample following reduction and prior to derivatization. Water and amino or hydroxyl containing solvents can inhibit the reaction. Extra care has been taken to include appropriate drying steps.

\section{4) SAFETY:}

a) Appropriate gloves and eye ware and fume hood space is required for handling solvents and acids.

b) Care is required in sparging and evacuating glass hydrolysis tubes to as to not over pressurize and rupture. Nitrogen gas pressure below 2 psi is recommended.

c) Weighing of active toxin-containing materials should be performed in a well ventilated hood. Toxin in whole seeds is generally inactivated by heat treatment at greater than $90^{\circ} \mathrm{C}$ for a minimum of 30 minutes prior to toxin extraction for safe sample handling during extraction, derivatization and analysis. 
d) Active toxins and the corresponding primary containers are decontaminated by placing all contaminated materials in a container of $1 \%$ commercial bleach in the biosafety cabinet.

e) During experiments with active toxin, all pipette tips, eppendorf tubes, instruments used to manipulate ricin-containing material and liquid waste will be placed in a container with a final concentration of $1 \%$ bleach in the biosafety cabinet. All deactivated waste is transferred to an accumulation container and incinerated.

f) All other solid waste (eg tissues, gloves, etc.) will be placed into the Biological Waste Disposal for autoclaving and incineration.

\begin{tabular}{lll}
\hline 5) APPARATUS: & & \\
\hline Apparatus & Item Number & Supplier \\
Reacti-Therm III Heat Block & 18835 & Pierce \\
Aluminum Blocks F & 18806 & Thermo \\
Aluminum Blocks S-1 & 18816 & Pierce \\
Aluminum Blocks B-1 & 18802 & Thermo \\
Vortex & G-560 & VWR Scientific \\
Centrifuge- Concentrator & SPD131DDA & Thermo \\
Centrifuge- Vacuum System & UVS800DDA & Thermo \\
Vacuum System (built in-house) & & \\
\hline
\end{tabular}

6) REAGENTS AND MATERIALS: All solvents should be of highest purity. All glassware used in the derivatization steps and those following must be rinsed in chloroform, toluene or methylene chloride prior to use.

\begin{tabular}{|c|c|c|}
\hline Supplies & Item Number & Supplier \\
\hline Beakers & & Fisherbrand \\
\hline Borosilicate test tubes (12x75mm) & $14-961-26$ & Fisherbrand \\
\hline C-18 columns (3mL) & 8B-S002-FBI & Phenomenex \\
\hline Chem Elute Columns (3mL) & 12198002 & Varian \\
\hline GC vials & $\mathrm{C} 400-2 \mathrm{~W}$ & National Scientific \\
\hline GC vial caps & C4000-54B & National Scientific \\
\hline GC vial insert LUI Spring & 401BS-530 & National Scientific \\
\hline Glass pipettes (Sterile, 1mL, 2mL) & $7077-1 \mathrm{~N}, 2 \mathrm{~N}$ & Pyrex \\
\hline Glass pipettes (Sterile, 10mL) & $13-678-27 F$ & Fisherbrand \\
\hline Hydrolysis tubes (5mL) & $896860-4010$ & Kimble Kontes \\
\hline Hydrolysis tube caps & $826601-4004$ & Kimble Kontes \\
\hline Pasteur pipettes 9" borosilicate & 13-678-20D & Fisherbrand \\
\hline pH paper & 9590 & EMD Chemicals \\
\hline Reaction vials (5mL) & 13223 & Pierce \\
\hline Reaction vial caps & 13223 & Thermo Scientific \\
\hline $\begin{array}{l}\text { Reaction vial Teflon laminated septum } \\
\text { disks }\end{array}$ & 12418 & Pierce \\
\hline Wiretrol- Micropipettes (100uL) & $5-000-1100$ & Drummond Scientific \\
\hline Chemicals & Item Number & Supplier \\
\hline
\end{tabular}


Acetic Acid

Acetic Anhyride

Acetonitrile

Ammonium Hydroxide

Chloroform

N,N Dioctylmethylamine

HPLC-Grade $\mathrm{H}_{2} \mathrm{O}$

Methanol

Sodium Borodeuterate

Sulfuric Acid
A6283

33085

34851

320145

650471

42430

365-4

320390

205591

339741
Sigma Aldrich

Supelco

Sigma

Sigma

Sigma

Aldrich

Sigma

Sigma

Aldrich

Aldrich

\section{7) SAMPLE COLLECTION, PRESERVATION AND HANDLING:}

a) Samples are kept in a cool dry environment prior to analysis to prevent microbial growth and sample breakdown. Handling of samples requires caution (see section 4. Safety).

b) Manipulation of the sample requires methanol rinsed spatulas or other metal devices.

c) For highly electrostatic samples, limited air flow during manipulation is necessary and metal aids in delivering the sample through the neck of the hydrolysis tube is required.

\section{8) STANDARDS AND CONTROLS:}

\section{External Standard}

6-Deoxy-D-glucose

D-(-)-Arabinose

D-(+)-Fucose

D-(+)-Galactose

D- Galactosamine HCL

D-(+)-Glucose

D-(+)-Glucosamine

D-(+)-Mannose

D-Mannosamine HCL

L-(+)-Rhamnose monohydrate

D-(-)-Ribose

D-(+)-Xylose

D-Pinitol

Muco-inositol

Allo-inositol

scyllo-inositol

D-(+)-chiro-inositol

Myo-inositol

Internal Standard

Methyl- $\alpha$-D Glucose

N-Methyl-D-Glucamine

\section{Item Number}

D-9761

A6085

F8150

G6404

G4875

G7528

G4875

M4670

M4670

83650

R-7500

X3877

441252

468061

468088

18132

468045

Not available

Item Number

M9376

M-2004

\section{Supplier}

Sigma

Sigma

Sigma

Sigma

Sigma

Sigma

Sigma

Sigma

Sigma

Fluka

Sigma

Sigma-Aldrich

Aldrich

Aldrich

Aldrich

Sigma

Aldrich

Chem Service

\section{Supplier}

Sigma

Sigma 
- Each standard was made at $2 \mathrm{mg} / \mathrm{mL}$ in $\mathrm{HPLC} \mathrm{H}_{2} \mathrm{O}$.

\section{9) CALIBRATION:}

a) A five point standard curve can be used to verify the linearity of response of all standards relative to the internal standards covering a two order of magnitude range of concentrations. This is performed by keeping the concentration of internal standards constant while varying the concentration of standards in the mixture to 10 fold less and 10 fold more than the internal standards.

b) A calibration curve is not required for quantitation due to the use of internal standards. The calculation of carbohydrate relative amount in percent dry weight relies on comparison of peak areas for unknown amounts of each constituent to the peak area of the known amount of internal standard to control for process variation. (see section 11).

\section{0) SAMPLING:}

$20 \mathrm{mg}$ of solid sample material is weighed out and placed into $5 \mathrm{~mL}$ hydrolysis tubes for processing. A blocked and randomized scheme is used for sample analysis including solvent blanks and external standards mixtures.

\section{1) OTHER QUALITY ASSURANCE CONSIDERATIONS:}

a) Using the standards run with each sample set, the retention times for each of the external and internal standards was determined. For each microliter of the standard mixture analyzed, $44.4 \mathrm{ng}$ of each external standard was delivered to the GC column. The peak areas as determined by the instrument software were used for quantitation.

b) All of the external standard and sample peaks were normalized to the response of the internal standards. The response factor of each external standard was determined by dividing the peak area of the external standard by the peak area of the internal standard. The neutral monosaccharides fucose, rhamnose, ribose, arabinose, deoxyglucose, xylose, mannose, galactose and glucose were compared to the internal standard methylglucose. The amino monosaccharides mannosamine, glucosamine and galactosamine were compared to the internal standard nmethylglucamine. An averaged response factor for each external standard was determined by averaging the response factors for each standard mix analyzed within a sample set.

$R F_{\text {std }}=\frac{\text { Area }_{\text {extstd }}}{\text { Area }_{\text {int std }}}$

i) Response factors for each known carbohydrate in the samples were calculated from the peak areas for the known carbohydrates in the samples divided by the internal standard peak areas in the samples.

$R F_{\text {sample }}=\frac{\text { Area }_{\text {carbpeak }}}{\text { Area }_{\text {int std }}}$

ii) The mass of each carbohydrate in the sample was calculated based on the carbohydrate response factor in the sample as compared to the response factor for $44.4 \mathrm{ng} / \mathrm{uL}$ of carbohydrate in the standard, multiplied by the sample volume to determine the total amount of each known carbohydrate in the sample.

(1) Where concstd = the concentration of the known standard in the standard mix in $n g / \mu \mathrm{L}$

(2) Volstd = the volume of standard mix injected

(3) Volsample $=$ the total sample volume of the final derivatized sample

(4) Masscarb = mass of the known carbohydrate in the final sample in nanograms.

mass $_{\text {carb }}=\frac{\left(\text { conc }_{\text {std }}\right)\left(\text { vol }_{\text {std }}\right)\left(R F_{\text {sample }}\right)\left(\text { vol }_{\text {sample }}\right)}{\left(R F_{\text {std }}\right)}$ 
iii) Finally, in the experiments in which a starting dry weight of the sample was determined, the $\%$ weight of each carbohydrate in the sample was calculated.

(1) Where both masscarb and masssample are in milligrams (mg).

$\% w t=\frac{\text { mass }_{\text {carb }}}{\text { mass }_{\text {sample }}} \times 100$

\section{2) PROCEDURE (Step-by-Step Directions)}

Prepare as needed:

$4 \mathrm{~N} \mathrm{H}_{2} \mathrm{SO}_{4}$ : Add $28 \mathrm{~mL}$ of $18 \mathrm{M} \mathrm{H}_{2} \mathrm{SO}_{4}$ to $250 \mathrm{~mL}$ of $\mathrm{HPLC} \mathrm{H}_{2} \mathrm{O}$

200:1 methanol:acetic acid: $400 \mathrm{~mL}$ methanol and $2 \mathrm{~mL}$ acetic acid in $1 \mathrm{~L}$ glass container

External Standard: Add $0.5 \mathrm{~mL}$ of each external standard $(2 \mathrm{mg} / \mathrm{ml})$ to a labeled glass vial for a final concentration of $111 \mathrm{ug} / \mathrm{mL}$.

Internal Standard: Add $1 \mathrm{~mL}$ of each internal standard $(2 \mathrm{mg} / \mathrm{mL})$ to a labeled glass vial for a final concentration of $1 \mathrm{mg} / \mathrm{mL}$.

Prepare each procedure:

On Day 1 make right before using during procedure:

(1) $50 \%$ N,N-dioctyl methyl amine: Add $24 \mathrm{~mL}$ of N,N-dioctylmethylamine to $24 \mathrm{~mL}$ chloroform

(2) Reducing agent: Add $150 \mathrm{mg}$ of sodium borodeuterate to $1.5 \mathrm{~mL} \mathrm{HPLC} \mathrm{H}_{2} \mathrm{O}$

\section{DAY 1 procedure:}

(1) Turn on heating block and set to $100^{\circ} \mathrm{C}$ (dial setting 5).

(2) Add $0.5 \mathrm{~mL}$ of sample to pre labeled hydrolysis tubes.

(3) Add $0.5 \mathrm{~mL}$ of $4 \mathrm{~N} \mathrm{H}_{2} \mathrm{SO}_{4}$ to each hydrolysis tube. Change tips with each sample to prevent cross contamination.

(4) Cap the hydrolysis tubes, but leave loose enough to allow gas flow in and out of hydrolysis chamber.

(5) Attach hydrolysis tubes to vacuum apparatus. Alternate between $\mathrm{N}_{2}$ and vacuum, quickly at first to ensure foam does not reach the top of the hydrolysis tube. Slow down after about 10 minutes and end with a 3 minute vacuum cycle. Do not allow the vacuum to pull the sample out of the tube.

(6) While leaving vacuum valve completely open, tighten the caps to retain vacuum in tubes.

(7) Remove hydrolysis tubes from vacuum apparatus and place into heating block. Do not touch the caps after sealing as they may loosen and lose vacuum.

(8) Hydrolyze for 3 hours at $100^{\circ} \mathrm{C}$. Ensure that the block temperature equilibrates at $100^{\circ} \mathrm{C}$ (this may take 20 minutes), and adjust temperature knob as necessary.

(9) Chloroform rinse reaction vials and test tubes $3 \mathrm{X}$ for next steps.

(10)During the last hour of hydrolysis, prepare (in triplicate) the working external standard. In a test tube add $100 \mu \mathrm{L}$ of external standard mixture to $400 \mu \mathrm{L}$ of $\mathrm{HPLC} \mathrm{H}_{2} \mathrm{O}$. Add 0.5 $\mathrm{mL}$ of $4 \mathrm{~N} \mathrm{H}_{2} \mathrm{SO}_{4}$ and $5 \mu \mathrm{L}$ of internal standard mixture.

(11) After 3 hours, remove hydrolysis tubes from heating block. Turn off heating block.

(12) Once tubes have cooled, twist off caps and check for vacuum on each sample.

(13) Using a Pasteur pipette, remove contents of each hydrolysis tube and place into its similarly labeled test tube. Put empty tubes and caps into soapy water, making sure to fill the inside of tubes.

(14) Add $1 \mathrm{~mL}$ of $\mathrm{HPLC} \mathrm{H}_{2} \mathrm{O}$ to each test tube. If sample is mash, add $\mathrm{H}_{2} \mathrm{O}$ to hydrolysis tube first before transferring to the test tube.

(15) Add $5 \mu \mathrm{L}$ of internal standard to each test tube. 


\section{Combined Castor Marker and Isotope Profile for Ricin Forensics: Final Report}

Page 44 of 57

(16) Add $2 \mathrm{~mL}$ of $50 \% \mathrm{~N}, \mathrm{~N}$-dioctylmethylamine to all test tubes.

(17) Vortex very well to neutralize acid.

(18) Place tubes into centrifuge and spin at 3000 rpm for 5 minutes to completely separate phases.

(19) While tubes are spinning, set up $3 \mathrm{~mL}$ C-18 columns:

(a) Make sure vacuum apparatus top and tubing are washed and rinsed thoroughly to avoid contamination.

(b) Assemble vacuum apparatus; attach tubing to vacuum, turn on vacuum knob.

(c) Insert C-18 columns into top holes.

(d) Run $2 \mathrm{~mL}$ of acetonitrile through each tube twice.

(e) Run $2 \mathrm{~mL}$ of HPLC $\mathrm{H}_{2} \mathrm{O}$ through each tube twice.

(f) Turn off vacuum and place numbered test tubes into apparatus and replace top.

(20) Remove samples from centrifuge and place in transport rack using care not to disrupt layers by shaking.

(21)For each sample, test top phase to ensure neutral $\mathrm{pH}$ (5-7) by placing one drop on $\mathrm{pH}$ paper. If neutral, transfer top phase into corresponding C-18 column number. Remaining phase goes to waste. Discard test tube.

(22) If sample is still acidic, add a few more drops of 50\% N,N-dioctylmethylamine, vortex and centrifuge again. Retest $\mathrm{pH}$. Repeat until neutral $\mathrm{pH}$.

(23) When all samples have been transferred onto the C-18 columns, turn on vacuum and pull sample through columns.

(24) Add $1 \mathrm{~mL}$ of HPLC $\mathrm{H}_{2} \mathrm{O}$ to each column and pull through.

(25) Turn off the vacuum and remove the top. Check each vial for any remaining N,Ndioctylmethylamine. Some cloudiness may have appeared and can be ignored.

(26) All glassware must be rinsed with chloroform $3 \mathrm{X}$ from here on out. No plastic is to be used.

(27) Transfer samples from test tubes to similarly labeled reaction vials.

(28) Weigh out $150 \mathrm{mg}$ of sodium borodeuterate and place in a test tube. Add $1.5 \mathrm{~mL}$ of HPLC $\mathrm{H}_{2} \mathrm{O}$ and shake until all the solid has dissolved.

(29) Using a $2 \mathrm{~mL}$ glass pipette, add $50 \mu \mathrm{L}$ (one drop) of the mixture to each reaction vial and cap tightly.

(30) Place samples in refrigerator overnight.

(31) Return sodium borodeuterate to desiccator and evacuate.

(32) Thoroughly wash and rinse vacuum apparatus top.

On Day 2 make right before using during procedure:

(1) If preparing 20 samples, have at least $80 \mathrm{ml}$ of a 200:1 methanol:acetic acid mixture prepared.

\section{DAY 2 Procedure:}

(1) Turn on heat block and set to $60-70^{\circ} \mathrm{C}$ (dial setting approx. 2 for Reacti-therms).

(2) Remove samples from the refrigerator.

(3) Add 0.5 mL of 200:1 methanol:acetic acid to each reaction vial.

(4) Place reaction vials in heating block and position $\mathrm{N}_{2}$ over the samples. Turn on gas. Ensure gas flow is high enough to cause surface of the samples to be indented by the flow, but not high enough to cause splashing across sample vials. Ensure good flow to all sample vials.

(5) After 30 minutes, add another $0.5 \mathrm{~mL}$ of methanol:acetic acid to each vial.

(6) Check block every 15 minutes to ensure temperature remains between $60-70^{\circ} \mathrm{C}$ and gas flow is set correctly.

(7) Add $0.5 \mathrm{~mL}$ of methanol:acetic acid about every 15 minutes until a total of $3 \mathrm{~mL}$ has been added. Do not allow samples to reach dryness before adding methanol:acetic acid. 
(8) Once the last addition of $0.5 \mathrm{~mL}$ of methanol:acetic acid is complete, leave vials under gas flow for at least 1 hour.

(9) Set heat block to $100^{\circ} \mathrm{C}$ (dial setting approx. 5). Make sure that the conclusion of the acetylation will be at a convenient time before starting the acetylation process. Adjust temperature knob to obtain a stable $100^{\circ} \mathrm{C}$ in the block (this may take 20-30 minutes).

(10) Add $0.3 \mathrm{~mL}$ acetic anhydride to each reaction vial and cap tightly. Swirl acetic anhydride around in each vial.

(11) Place samples in the heat block to acetylate for 13-16 hours.

On Day 3: make right before using during procedure:

(1) If preparing 20 samples, have at least $30 \mathrm{ml}$ of $30 \%$ ammonium hydroxide prepared.

\section{DAY 3 Procedure:}

(1) After acetylation is complete, remove the reaction vials from the heating block. Turn off heat block.

(2) Once vials have cooled, add $0.75 \mathrm{~mL} \mathrm{HPLC} \mathrm{H}_{2} \mathrm{O}$ to each vial and recap.

(3) Place vials into shaker at $150 \mathrm{rpm}$ for $\mathbf{1}$ hour at room temperature.

(4) Add $1 \mathrm{~mL}$ of chloroform to each vial and recap.

(5) Shake vials for another 5 minutes.

(6) Let vials stand for 20 minutes to allow complete separation of phases.

(7) Pipette off the top aqueous phase to waste (some aqueous layer may remain, it will be removed by the Chem-Elut columns in step 10).

(8) Add $0.8 \mathrm{~mL}$ cold $30 \%$ ammonium hydroxide to each vial.

(9) Working with one vial at a time, recap and vortex to thoroughly mix in the base. Using a Pasteur pipette, transfer the contents to a Chem-Elut column above the similarly labeled borosilicate test tube. Place reaction vial and caps in soapy water.

(10) Once all samples have been added to the Chem-Elut columns, add $2 \mathrm{~mL}$ of chloroform to each column. Chloroform should work its way through the column and begin dripping from the bottom into the vials below.

(11) When all the chloroform has percolated through the columns so that the columns are no longer dripping into the test tubes, add another $2 \mathrm{~mL}$ of chloroform to each column.

(12) Once all of the columns have stopped dripping, remove the columns and discard.

(13) Place test tubes into heat block (NO HEAT) and position $\mathrm{N}_{2}$ over the vials.

(14) Turn on $\mathrm{N}_{2}$ so it is indenting the surface of the samples.

(15) Evaporate to dryness, about 1 hour.

(16) Reconstitute the samples in $0.25 \mathrm{~mL}$ of chloroform. Transfer $50 \mu \mathrm{L}$ of sample to labeled target vial with insert. Add remaining sample to another target vial without insert and place in freezer until analyzed.

\section{a) GC-MS Analysis}

i) CTC Pal Autosampler with 10uL liquid syringe. Settings:

Air Volume: 1uL

Pre-clean with Solvent $15 x$ (Solvent 1 is toluene)

Pre-clean with Solvent 2 5x (Solvent 2 is methylene chloride)

Solvent Fill - 50\%

Pre-clean with sample $2 \mathrm{x}$

Sample Fill: $1 \mathrm{uL}$

Filling speed: $2 \mathrm{uL} / \mathrm{s}$

Filling strokes: 5

Inject to split/splitless inlet

Injection speed: $50 \mathrm{uL} / \mathrm{s}$ 
(11)
Pre Inject delay: 100ms

Post inject delay: $100 \mathrm{~ms}$

Post clean with solvent 1: $10 \mathrm{x}$

Post clean with solvent 2: 10x

Pullup delay: $100 \mathrm{~ms}$

ii) GC Parameters

(1) Oven:

(a) $100^{\circ} \mathrm{C}$ for $1 \mathrm{~min}$

(b) $2.5^{\circ} \mathrm{C} / \mathrm{min}$ to $225^{\circ} \mathrm{C}$

(c) $25^{\circ} \mathrm{C} / \mathrm{min}$ to $250^{\circ} \mathrm{C}$ hold for $5 \mathrm{~min}$

(d) Run Time 57 min.

(2) Split/Splitless inlet:

(a) He carrier

(b) Heater on, $250^{\circ} \mathrm{C}$

(c) Septum purge flow $3 \mathrm{~mL} / \mathrm{min}$

(d) Split ratio: 10:1

(e) Split flow: $12 \mathrm{~mL} / \mathrm{min}$

(f) Column:

(i) HP-5MS (or equivalent): $30 \mathrm{~m}$ x $250 \mathrm{um} \times 0.25 \mathrm{um}$

(ii) Constant flow, $1.089 \mathrm{~mL} / \mathrm{min}$

iii) MS Parameters

(1) Solvent delay: 5 minutes

(2) Acquisition mode: scan

(3) EMV mode: gain factor

(4) Gain factor $=1.00$, resulting EM voltage $=1059$

(5) Scan parameters: $35-250 \mathrm{amu}$

(6) MS transferline: $250^{\circ} \mathrm{C}$

(7) MS source: $230^{\circ} \mathrm{C}$

(8) MS quad: $150^{\circ} \mathrm{C}$

\section{3) METHOD PERFORMANCE:}

a) The method performance is evaluated by preparation of at least five replicate $20 \mathrm{mg}$ samples derivatized for a single bean type.

b) The markers arabinose, xylose, myo-inositol, chiro-inositol, rhamnose, fucose, mannose, galactose, glucose and glucosamine should be observed in both crude seed extracts and solvent extracted mash.

i) The identity of each compound in the sample is confirmed by matching retention time and mass spectrum to those of the same compound in the external standard mixture.

(1) Retention times will be within 0.25 min of the corresponding peak from the standard mixture.

(2) The mass spectrum of the peak in the sample shall share the five most abundant ions with the mass spectrum of the corresponding peak from the standard mixture.

c) The relative standard deviation (RSD) for quantity measurements for each carbohydrate should be less than $30 \%$.

d) The minimum quantifiable levels are at least $0.01 \%$ dry weight.

\section{4) REFERENCES}


1. A F, L MS, J G, editors (1989) Preparation of alditol acetates and their analysis by gas chromatography and mass spectrometry. FL: CRC Press. p.p. 87117 p.

2. Fox A, Black GE, Fox K, Rostovtseva S (1993) Determination of carbohydrate profiles of Bacillus anthracis and Bacillus cereus including identification of O-methyl methyl pentoses by using gaschromatography mass spectrometry. . Journal of Clinical Microbiology 31: 887-894.

3. Wunschel D, Fox KF, Black GE, Fox A (1994) Discrimination among the B. cereus group, in comparison to B. subtilis, by structural carbohydrate profiles and ribosomal RNA spacer region PCR. Systematic and Applied Microbiology 17: 625-635.

4. Wunschel DS, Colburn HA, Fox A, Fox KF, Harley WM, et al. (2008) Detection of agar, by analysis of sugar markers, associated with Bacillus anthracis spores, after culture. Journal of Microbiological Methods 74: 57-63. 


\subsection{Appendix D}

\begin{tabular}{|l|l|}
\hline DHS Chemical Forensics Program & Procedure \#: PNNLCHO-TMS-063009 \\
\cline { 2 - 2 } STANDARD ANALYTICAL METHOD & Date of Issue: June 30, 2009 Page 48 of \\
\cline { 2 - 2 } & Revision \#: 1 \\
& 57 \\
\hline Title: Preparation and Analysis of Trimethylsilyl \\
Carbohydrate Derivatives from Castor Samples \\
\hline
\end{tabular}

Prepared by: David S. Wunschel* Ph. D., Angie Melville, and Heather Colburn Ph. D.

*Contact Information: PO Box 999 MS P8-13, Richland WA, 99354.

David.Wunschel@pnl.gov; (509) 372-2951

Prepared at: Pacific Northwest National Laboratory, Richland WA.

Introductory Notes/Comments:

This method is written to create trimethylsilyl (TMS) derivatives from carbohydrates found in forensic samples. It is written as a partner method to two other methods for derivatization and analysis of carbohydrates as alditol acetates (PNNLCHO-AA-063009) and fatty acids as methyl esters (PNNLFAME-063009). The method is constructed from previous experience with a method for analysis of bacterial sugars as alditol acetates ${ }^{18,22}$ and modifying the derivatizing reaction to create TMS derivatives $\left.{ }^{24-27}\right]$.

The acquisition of instrument data on the identity, abundance and isotope ratio of these compounds will utilize two different types of instrumentation. A gas chromatograph mass spectrometer (GC-MS) is the intended type of instrument used for obtaining marker identity and relative abundance. A more specialized analysis to measure the stable hydrogen/deuterium and ${ }^{18} \mathrm{O} /{ }^{16} \mathrm{O}$ isotope ratios by gas chromatography isotope ratio mass spectrometry (GC-IRMS) is possible for the fatty acid methyl esters and TMS derivatized carbohydrates. The specific instrument parameters used to obtain isotope ratio information for the markers of interest using the GC-IRMS will be compiled in a separate standard analytical method.

Care is required in the maintenance of laboratory equipment and supplies to prevent introduction of extraneous compounds and carryover between samples. Steps are required, such as cleaning vacuum manifolds used for solid phase extraction (SPE) sample cleanup, acid washing of glassware (particularly hydrolysis tubes) and chloroform rinsing of all glassware such as pipettes and reaction vials that touch the final derivatized sugars.

This method is described with a preliminary description of its performance. The method will be evaluated and more completely defined performance criteria established after testing against a standard set of samples in FY09. 


\section{SCOPE AND APPLICATION:}

This method focuses on analysis of samples containing the plant toxin ricin, which is derived from castor seeds ( $R$. communis). The principle behind this method is the measurement of carbohydrate markers indicating the relative loss of various portions of the source material (castor seed) with ricin processing steps. During purification of the protein toxin ricin, portions of the seed are removed. Components such as castor oil, starch, cell wall material and soluble disaccharides, oligosaccharides and cyclitols (present for dessication resistance) are removed with increasingly pure toxin preparations. Measuring the type and relative abundance of markers can determine if the sample underwent processing to remove the carbohydrate containing fractions.

The method focuses on preparation of solid samples for carbohydrate analysis by GC-MS or GC-IRMS. The data produced by GC-MS will be a relative quantitation (percent dry weight) of monomeric carbohydrates derived in the sample following hydrolysis reduction and derivatization of the neutral and amino monosaccharides. Additionally, the ${ }^{18} \mathrm{O} /{ }^{16} \mathrm{O}$ stable isotope ratio data can be obtained from the same derivatized compounds. A preliminary evaluation of the performance criteria will be given, but is subject to the method testing in the FY09.

\section{SUMMARY OF METHOD:}

This method relies on first liberating any sugar monomers (e.g. glucose, inositol, arabinose, mannose, etc.) from any oligomeric or polymeric structures that may be bound within using acid hydrolysis. Examples of target compounds are the glucose-rich starch, inositol of phospholipids and "cyclitol” disaccharides, xylose/ arabinose rich hemicellulose polymers within the cell wall and the mannose rich protein glycosylation.

Following acid hydrolysis, the samples are neutralized using an organic base and hydrophobic contaminants are removed by solid phase extraction. The aldose and ketose (C-1 carbonyl containing) sugars are then reduced to their alditol form using sodium borodeuteride. The use of the borodeuteride adds a deuterium to the C-1 carbon, allowing native aldoses and ketose carbohydrates to be distinguished from native alditols in the mass spectrum (glucose is distinguishable from glucitol). The C-1 containing fragment masses are $1 \mathrm{~m} / \mathrm{z}$ larger for aldoses (e.g. glucose) than those found for native alcohol sugars (e.g. glucitol).

Following reduction, the residual borodeuteride is removed by addition of methanol-acetic acid addition to dry it away as tetra methyl borate gas. The result is residual sodium and acetate. Derivatization of the reduced sugars to their trimethylsilyl form can then take place by resuspending them in pyridine and adding the $\mathrm{N}$,O-bis (Trimethylsilyl) trifluoroacetamide (BSTFA) with Trimethylchlorosilane (TCMS) derivatizing reagent.

Following a short, room-temperature, incubation step the products are ready for direct analysis by GC-MS. This method can detect a wide range of neutral carbohydrate markers from as little as $20 \mathrm{mg}$ of sample.

This method was not developed with the analysis of amino or acidic sugars in mind, although further alterations may make that possible in the future. The derivatives are anticipated to be stable at $4 \mathrm{C}$ for up to a month for reanalysis.

\section{INTERFERENCES:}

The method relies on having clean, solvent rinsed glassware for preparation of the derivatives.

The presence of water in the sample following reduction and prior to derivatization. Water and amino or hydroxyl containing solvents can inhibit the reaction. Extra care has been taken to include appropriate drying steps. 

lifetime.

Exposure of the derivatized compounds to water or extended exposure to air may reduce their

\section{SAFETY:}

acids.

Appropriate gloves and eye ware and fume hood space is required for handling solvents and

Care is required in sparging and evacuating glass hydrolysis tubes so as to not over pressurize and rupture. Nitrogen gas pressure below 2 psi is recommended.

Weighing of active toxin-containing materials should be performed in a well ventilated hood.

Toxin in whole seeds is generally inactivated by heat treatment at greater than $90^{\circ} \mathrm{C}$ for a minimum of 30 minutes prior to toxin extraction for safe sample handling during extraction, derivatization and analysis.

Active toxins and the corresponding primary containers are decontaminated by placing all contaminated materials in a container of $1 \%$ of commercial bleach in the biosafety cabinet

During experiments with active toxin, all pipette tips, eppendorf tubes, instruments used to manipulate ricin-containing material and liquid waste will be placed in a container with a final concentration of $1 \%$ bleach in the biosafety cabinet.

All other solid waste (e.g. tissues, gloves, etc.) will be placed into the Biological Waste Disposal for autoclaving.

\begin{tabular}{lll|}
\hline \multicolumn{1}{|c}{ APPARATUS: } & & \\
\hline Apparatus & Item Number & Supplier \\
Reacti-Therm III Heat Block & 18835 & Pierce \\
Aluminum Blocks F & 18806 & Thermo \\
Aluminum Blocks S-1 & 18816 & Pierce \\
Aluminum Blocks B-1 & 18802 & Thermo \\
Vortex & G-560 & VWR Scientific \\
Centrifuge- Concentrator & SPD131DDA & Thermo \\
Centrifuge- Vacuum System & UVS800DDA & Thermo \\
Vacuum System (built in-house) & & \\
\hline
\end{tabular}

REAGENTS AND MATERIALS: All solvents should be of highest purity. All glassware used in the derivatization steps and those following must be rinsed in chloroform, toluene or methylene chloride prior to use.

\begin{tabular}{|c|c|c|}
\hline Supplies & Item Number & Supplier \\
\hline Beakers & & Fisherbrand \\
\hline Borosilicate test tubes $(12 \times 75 \mathrm{~mm})$ & $14-961-26$ & Fisherbrand \\
\hline C-18 columns (3mL) & 8B-S002-FBI & Phenomenex \\
\hline Chem Elute Columns (3mL) & 12198002 & Varian \\
\hline $\begin{array}{l}\text { Amber autosampler vials w/caps, } \\
100 \mu \mathrm{L} \text { glass inserts with polypropylene }\end{array}$ & $5188-6535$ & Agilent \\
\hline spring & 24508 & Restek \\
\hline Glass pipettes (Sterile, 1mL, 2mL) & $7077-1 \mathrm{~N}, 2 \mathrm{~N}$ & Pyrex \\
\hline Glass pipettes (Sterile, 10mL) & $13-678-27 \mathrm{~F}$ & Fisherbrand \\
\hline Hydrolysis tubes (5mL) & $896860-4010$ & Kimble Kontes \\
\hline Hydrolysis tube caps & $826601-4004$ & Kimble Kontes \\
\hline Pasteur pipettes 9" borosilicate & 13-678-20D & Fisherbrand \\
\hline
\end{tabular}




pH paper
Reaction vials (5mL) with vial
Reaction vial Teflon laminated
disks
70 mm cellulose filters (Grade 1 )
Rubber bands
Wiretrol- Micropipettes (100uL)
Chemicals
Acetic Acid
Acetic Anhyride
Acetonitrile
Ammonium Hydroxide
Chloroform with amylenes
N,N Dioctylmethylamine
HPLC-Grade H20
Methanol
Sodium Borodeuterate
Sulfuric Acid
BSTFA w/1\% TMCS
Pryidine
Toluene

9590

TS13223

12418

$1001-070$

5-000-1100

Item Number

A6283

33085

34998

320145

650498

42430

365-4

320390

205591

339741

38831

347-1
EMD Chemicals

Pierce

Pierce

Whatman

Drummond Scientific

Supplier

Sigma Aldrich

Supelco

Sigma-Aldrich

Sigma

Sigma-Aldrich

Aldrich

Sigma

Sigma

Aldrich

Aldrich

Thermo Scientific

Alltech

Burdick \& Jackson

\section{SAMPLE COLLECTION, PRESERVATION AND HANDLING:}

Samples are kept in a cool dry environment prior to analysis to prevent microbial growth and sample breakdown. Handling of samples requires caution (see section 4. Safety).

Manipulation of the sample requires methanol rinsed spatulas or other metal devices.

For highly electrostatic samples, limited air flow during manipulation is necessary and metal aids in delivering the sample through the neck of the hydrolysis tube is required.

\section{STANDARDS AND CONTROLS:}

Methyl- $\alpha$-D-Gluco pyranoside, Sigma M9376 - internal standard

D-(-)-Ribose, Sigma R7500

D-(+)-Xylose, Sigma-Aldrich X3877

D-(-)-Arabinose, Sigma A3131

L-Rhamnose monohydrate, Sigma R3875

D-(+)-Fucose, Sigma F8150

D-(+)-Glucose, Sigma G7528

D-(+)-Galactose, Sigma G6404

D-(+)-Mannose, Sigma M4625

Myo-inositol, Chem Service

Muco-inositol, Aldrich 468061

D-(+)-Chiro-inositol, Aldrich 468045

Scyllo-inositol, Sigma I8132

D-Pinitol, Aldrich 441252 


\section{CALIBRATION:}

A five point standard curve can be used to verify the linearity of response of all standards relative to the internal standards covering a two order of magnitude range of concentrations. This is performed by keeping the concentration of internal standards constant while varying the concentration of standards in the mixture to 10 fold less and 10 fold more than the internal standards.

A calibration curve is not required for quantitation due to the use of internal standards. The calculation of carbohydrate relative amount in percent dry weight relies on comparison of peak areas for unknown amounts of each constituent to the peak area of the known amount of internal standard to control for process variation. (see section 11).

\section{SAMPLING:}

$100 \mathrm{mg}$ of solid sample material is weighed out and placed into $5 \mathrm{~mL}$ hydrolysis tubes for processing. A blocked and randomized scheme is used for sample analysis including solvent blanks and external standards mixtures.

\section{OTHER QUALITY ASSURANCE CONSIDERATIONS:}

Using the standards run with each sample set, the retention times for each of the external and internal standards was determined. For each microliter of the standard mixture analyzed, $60 \mathrm{ng}$ of each external standard was delivered to the GC column. The peak areas as determined by the instrument software were used for quantitation.

All of the external standard and sample peaks were normalized to the response of the internal standards. The response factor of each external standard was determined by dividing the peak area of the external standard by the peak area of the internal standard. The neutral monosaccharides fucose, rhamnose, ribose, arabinose, deoxyglucose, xylose, mannose, galactose and glucose were compared to the internal standard methylglucose. The amino monosaccharides mannosamine, glucosamine and galactosamine were compared to the internal standard n-methylglucamine. An averaged response factor for each external standard was determined by averaging the response factors for each standard mix analyzed within a sample set.

$$
R F_{\text {std }}=\frac{\text { Area }_{\text {extstd }}}{\text { Area }_{\text {int std }}}
$$

Response factors for each known carbohydrate in the samples were calculated from the peak areas for the known carbohydrates in the samples divided by the internal standard peak areas in the samples.

$$
R F_{\text {sample }}=\frac{\text { Area }_{\text {carbpeak }}}{\text { Area }_{\text {int std }}}
$$

The mass of each carbohydrate in the sample was calculated based on the carbohydrate response factor in the sample as compared to the response factor for $60 \mathrm{ng} / \mathrm{uL}$ of carbohydrate in the standard, multiplied by the sample volume to determine the total amount of each known carbohydrate in the sample.

(1) Where concstd = the concentration of the known standard in the standard mix in $\mathrm{ng} / \mu \mathrm{L}$

(2) Volstd = the volume of standard mix injected

(3) Volsample $=$ the total sample volume of the final derivatized sample

(4) Masscarb = mass of the known carbohydrate in the final sample in nanograms.

$$
\text { mass }_{\text {carb }}=\frac{\left(\text { conc }_{\text {std }}\right)\left(\text { vol }_{\text {std }}\right)\left(R F_{\text {sample }}\right)\left(\text { vol }_{\text {sample }}\right)}{\left(R F_{\text {std }}\right)}
$$

Finally, in the experiments in which a starting dry weight of the sample was determined, the \% weight of each carbohydrate in the sample was calculated. 
(1) Where both masscarb and masssample are in milligrams (mg).

$\% w t=\frac{\text { mass }_{\text {carb }}}{\text { mass }_{\text {sample }}} \times 100$

\section{PROCEDURE (Step-by-Step Directions)}

Prepare as needed:

$4 \mathrm{~N} \mathrm{H}_{2} \mathrm{SO}_{4}$ : Add $28 \mathrm{~mL}$ of $18 \mathrm{M} \mathrm{H}_{2} \mathrm{SO}_{4}$ to $250 \mathrm{~mL}$ of $\mathrm{HPLC} \mathrm{H}_{2} \mathrm{O}$

200:1 methanol:acetic acid: $400 \mathrm{~mL}$ methanol and $2 \mathrm{~mL}$ acetic acid in $1 \mathrm{~L}$ glass container

External Standard: Add $0.5 \mathrm{~mL}$ of each external standard $(2 \mathrm{mg} / \mathrm{ml})$ to a labeled glass vial for a final concentration of $111 \mathrm{ug} / \mathrm{mL}$.

Internal Standard: Add $1 \mathrm{~mL}$ of each internal standard $(2 \mathrm{mg} / \mathrm{mL})$ to a labeled glass vial for a final concentration of $1 \mathrm{mg} / \mathrm{mL}$.

Prepare each procedure:

On Day 1: make right before using during procedure:

(1) $50 \% \mathrm{~N}, \mathrm{~N}$-dioctyl methyl amine: Add $24 \mathrm{~mL}$ of N,N-dioctylmethylamine to $24 \mathrm{~mL}$ chloroform

(2) Reducing agent: Add $150 \mathrm{mg}$ of sodium borodeuterate to $1.5 \mathrm{~mL} \mathrm{HPLC} \mathrm{H}_{2} \mathrm{O}$

\section{DAY 1 Procedure:}

(1) Turn on heating block and set to $100^{\circ} \mathrm{C}$ (dial setting 5).

(2) Add $100 \mathrm{mg}$ of castor mash to pre labeled hydrolysis tubes.

(3) Add $0.5 \mathrm{~mL}$ HPLC $\mathrm{H}_{2} \mathrm{O}$ to each hydrolysis tube. Change tips with each sample to prevent cross contamination. Use the water to wash the mash down to the bottom if it is stuck on the sides of the tube.

(4) Add $0.5 \mathrm{~mL}$ of $4 \mathrm{~N} \mathrm{H}_{2} \mathrm{SO}_{4}$ to each hydrolysis tube. Change tips with each sample to prevent cross contamination.

(5) Cap the hydrolysis tubes, but leave loose enough to allow flow in and out.

(6) Attach hydrolysis tubes to vacuum apparatus. Alternate between $\mathrm{N}_{2}$ and vacuum, quickly at first to ensure foam does not reach the top of the hydrolysis tube. Slow down after about 10 minutes and end with a 3 minute vacuum cycle. Do not allow the vacuum to pull the sample out of the tube.

(7) While leaving vacuum valve completely open, tighten the caps to retain vacuum in tubes.

(8) Remove hydrolysis tubes from vacuum apparatus and place into heating block. Do not touch the caps after sealing as they may loosen and lose vacuum.

(9) Hydrolyze for 3 hours at $100^{\circ} \mathrm{C}$. Ensure that the block temperature equilibrates at $100^{\circ} \mathrm{C}$ (this may take 20 minutes), and adjust temperature knob as necessary.

(10)Chloroform rinse reaction vials and test tubes $3 \mathrm{X}$ for next steps.

(11) During the last hour of hydrolysis, prepare (in triplicate) working external standard. In a test tube add $100 \mu \mathrm{L}$ of external standard mixture to $400 \mu \mathrm{L}$ of $\mathrm{HPLC} \mathrm{H}_{2} \mathrm{O}$. Add $0.5 \mathrm{~mL}$ of $4 \mathrm{~N} \mathrm{H}_{2} \mathrm{SO}_{4}$ and $25 \mu \mathrm{L}$ of internal standard mixture.

(12) After 3 hours, remove hydrolysis tubes from heating block. Turn off heating block.

(13) Once tubes have cooled, twist off caps and check for vacuum on each sample.

(14) Add $1 \mathrm{~mL}$ of HPLC $\mathrm{H}_{2} \mathrm{O}$ to each hydrolysis tube.

(15) Using a Pasteur pipette, remove contents of each hydrolysis tube and place into its similarly labeled test tube. Put empty tubes and caps into soapy water, making sure to fill the inside of tubes.

(16) Add $25 \mu \mathrm{L}$ of internal standard to each test tube.

(17) Add $2 \mathrm{~mL}$ of $50 \% \mathrm{~N}$,N-dioctylmethylamine to all test tubes.

(18) Vortex very well to neutralize acid.

(19) Place tubes into centrifuge and spin at $3000 \mathrm{rpm}$ for 5 minutes to completely separate phases. 
(20) All glassware must be rinsed with chloroform $3 \mathrm{X}$ following the C-18 cleanup. No plastic is to be used.

(21) Presilanize reaction vials by rinsing $3 X$ in toluene, add $1 \mathrm{~mL}$ TMS reagent, cap and vortex. Let sit 1 hour. Rinse vials $1 \mathrm{X}$ with toluene

(22) While tubes are spinning, set up $3 \mathrm{~mL} \mathrm{C-18}$ columns:

(a) Make sure vacuum manifold top and tubing are washed and rinsed thoroughly to avoid contamination.

(b) Assemble vacuum manifold, attach tubing to vacuum, turn on vacuum knob.

(c) Insert C-18 columns into top holes.

(d) Run $2 \mathrm{~mL}$ of acetonitrile through each tube twice.

(e) Run $2 \mathrm{~mL}$ of HPLC $\mathrm{H}_{2} \mathrm{O}$ through each tube twice.

(f) Turn off vacuum and place numbered test tubes into manifold and replace top.

(23) Remove samples from centrifuge and place in transport rack using care not to disrupt layers by shaking.

(24)For each sample, test top phase to ensure neutral $\mathrm{pH}$ (5-7) by placing one drop on $\mathrm{pH}$ paper. If neutral, transfer top phase into corresponding C-18 column number. Remaining phase goes to waste. Discard test tube.

(25) If sample is still acidic, add a few more drops of $50 \% \mathrm{~N}, \mathrm{~N}$-dioctylmethylamine, vortex and centrifuge again. Retest $\mathrm{pH}$. Repeat until neutral $\mathrm{pH}$.

(26) When all samples have been transferred onto the C-18 columns, turn on vacuum and pull sample through columns.

(27) Add $1 \mathrm{~mL}$ of HPLC $\mathrm{H}_{2} \mathrm{O}$ to each column and pull through.

(28) Turn off the vacuum and remove the top. Check each vial for any remaining N,Ndioctylmethylamine. Some cloudiness may have appeared and can be ignored.

(29) Transfer samples from test tubes to similarly labeled reaction vials.

(30) Weigh out $150 \mathrm{mg}$ of sodium borodeuteride and place in a test tube. Add $1.5 \mathrm{~mL}$ of HPLC $\mathrm{H}_{2} \mathrm{O}$ and shake until all the solid has dissolved.

(31) Using a $2 \mathrm{~mL}$ glass pipette, add $50 \mu \mathrm{L}$ (one drop) of the mixture to each reaction vial and cap tightly.

(32) Place samples in refrigerator overnight.

(33) Return sodium borodeuteride to dessicator and evacuate.

(34) Thoroughly wash and rinse vacuum manifold top.

On Day 2: make right before using during procedure

(1) If preparing 20 samples, have at least $80 \mathrm{ml}$ of a 200:1 methanol:acetic acid mixture prepared.

\section{DAY 2 Procedure:}

(1) Turn on heat block and set to $60-70^{\circ} \mathrm{C}$ (dial setting approx. 2).

(2) Remove samples from the refrigerator.

(3) Add 0.5 mL of 200:1 methanol:acetic acid to each reaction vial.

(4) Place reaction vials in heating block and position $\mathrm{N}_{2}$ over the samples. Turn on gas. Make sure gas flow is high enough to cause surface of the samples to be indented by the flow, but not high enough to cause splashing across sample vials. Ensure good flow to all sample vials.

(5) For the last few steps, rinse pipettes with toluene, not chloroform.

(6) After 30 minutes, add another $0.5 \mathrm{~mL}$ of methanol:acetic acid to each vial. Check block every 15 minutes to ensure temperature remains between $60-70^{\circ} \mathrm{C}$ and gas flow is set correctly. 


\section{Combined Castor Marker and Isotope Profile for Ricin Forensics: Final Report}

Page 55 of 57

(7) Add $0.5 \mathrm{~mL}$ of methanol:acetic acid about every 15 minutes until a total of $3 \mathrm{~mL}$ has been added. Do not allow samples to reach dryness before adding methanol:acetic acid.

(8) Once the last addition of $0.5 \mathrm{~mL}$ of methanol:acetic acid is complete, leave vials under gas flow for at least 1 hour.

(9) Place a filter over vial, instead of the cap, with rubber band and poke a few holes in the top.

(a) Alternative methods of covering the vials may be suitable.

(10) Lyophilize for 1 hour.

(11) Add $150 \mu \mathrm{L}$ of pyridine and $150 \mu \mathrm{L}$ BSTFA to each vial, cap and vortex for a few seconds.

(12) Let sit at room temperature for 1 hour.

(13) Transfer $150 \mu \mathrm{L}$ of sample to labeled target vial with insert. Add remaining sample to another target vial with insert and place in freezer until analyzed.

\section{GC-MS Analysis}

CTC Pal Autosampler with 10uL liquid syringe. Settings:

Air Volume: 1uL

Pre-clean with Solvent $15 x$ (Solvent 1 is toluene)

Pre-clean with Solvent $25 x$ (Solvent 2 is methylene chloride)

Solvent Fill - 50\%

Pre-clean with sample $2 \mathrm{x}$

Sample Fill: 1uL

Filling speed: $2 \mathrm{uL} / \mathrm{s}$

Filling strokes: 5

Inject to split/splitless inlet

Injection speed: $50 \mathrm{uL} / \mathrm{s}$

Pre Inject delay: $100 \mathrm{~ms}$

Post inject delay: $100 \mathrm{~ms}$

Post clean with solvent 1: $10 \mathrm{x}$

Post clean with solvent 2: 10x

Pullup delay: $100 \mathrm{~ms}$

GC Parameters

(1) Oven:
(a) $100^{\circ} \mathrm{C}$ for $1 \mathrm{~min}$
(b) $2.5^{\circ} \mathrm{C} / \mathrm{min}$ to $225^{\circ} \mathrm{C}$
(c) $25^{\circ} \mathrm{C} / \mathrm{min}$ to $250^{\circ} \mathrm{C}$ hold for $5 \mathrm{~min}$
(d) Run Time 57 min.

(2) Split/Splitless inlet:
(a) He carrier
(b) Heater on, $250^{\circ} \mathrm{C}$
(c) Septum purge flow $3 \mathrm{~mL} / \mathrm{min}$
(d) Split ratio: 10:1
(e) Split flow: $12 \mathrm{~mL} / \mathrm{min}$
(f) Column:

(i) HP-5MS (or equivalent): $30 \mathrm{~m}$ x $250 \mathrm{um} \times 0.25 \mathrm{um}$

(ii) Constant flow, $1.089 \mathrm{~mL} / \mathrm{min}$ 


\section{Combined Castor Marker and Isotope Profile for Ricin Forensics: Final Report}

Page 56 of 57

MS Parameters

(1) Solvent delay: 5 minutes

(2) Acquisition mode: scan

(3) EMV mode: gain factor

(4) Gain factor $=1.00$, resulting EM voltage $=1059$

(5) Scan parameters: $35-250 \mathrm{amu}$

(6) MS transferline: $250^{\circ} \mathrm{C}$

(7) MS source: $230^{\circ} \mathrm{C}$

(8) MS quad: $150^{\circ} \mathrm{C}$

\section{METHOD PERFORMANCE:}

The method performance is evaluated by preparation of at least five replicate $100 \mathrm{mg}$ samples derivatized for a single bean type.

The markers arabinose, xylose, myo-inositol, chiro-inositol, rhamnose, fucose, mannose, galactose and glucose should be observed in both crude bean extracts and solvent extracted mash.

The identity of each compound in the sample is confirmed by matching retention time and mass spectrum to those of the same compound in the external standard mixture.

(1) Retention times will be within 0.25 min of the corresponding peak from the standard mixture.

(2) The mass spectrum of the peak in the sample shall share the five most abundant ions with the mass spectrum of the corresponding peak from the standard mixture.

\section{REFERENCES}

(1) Lundger, S., L Melin, C Nilsson, P von Shoenberg. : Umea, SE, 2004.

(2) Amukele, T. K.; Roday, S.; Schramm, V. L. Biochemistry 2005, 44, 4416-4425.

(3) 42 ed.; Services, D. o. H. a. H., Ed.: Washington, DC, 2002; Vol. vol 240, pp Part 1003.

(4) In Biosafety in Microbiological and Biomedical Laboratories Handbook; Millard., E. C. B., Ed., 2005; Vol. 5th edition, pp pp 1-14.

(5) Kamimura R, S. V., Final Report ed.; Lawrence Livermore National Laboratory.: Livermore, CA, 2005.

(6) Weiss, E. A. Oilseed crops; Longman: London and New York, 1983.

(7) Ogunniyi, D. S. Bioresource Technology 2006, 97, 1086-1091.

(8) InfernoMDM.; Temple of the Screaming Electron (TOTSE) 2004; Vol. 2004.

(9) Harber, D. In Assorted Nasties; Desert Publications: El Dorado, AR 71731, 1993.

(10) Simmons, B., JH Russell Analytical Biochemistry 1984, 146, 206-210.

(11) Saxon, K. The Poor Man's James Bond; Desert Publications: El Dorado, AR 71730, 1991.

(12) Preisler, S. In Silent Death; Festering Publications: Green Bay, WI 54301, 1997; Vol. Chapter 10.

(13) Craig, H., OH Alderks, AH Germin, SH Dieke, CL Karel. : USA, 1952.

(14) NAUGHTON, F. C. In Kirk-Othmer Encyclopedia of Chemical Technology., Fifth Edition ed.; John Wiley \& Sons, Inc., 1993, pp 1-17.

(15) Horobowicz, M. a. R. O. Seed. Sci. Res. 1994, 4, 385-405.

(16) Esteves, B.; Graca, J.; Pereira, H. Holzforschung 2008, 62, 344-351.

(17) Nagahashi, J.; Browder, S. K.; Beevers, L. Plant Physiology 1980, 65, 648-657.

(18) Fox, A.; Black, G. E.; Fox, K.; Rostovtseva, S. Journal of Clinical Microbiology 1993, 31, 887894.

(19) Wunschel, D.; Fox, K. F.; Black, G. E.; Fox, A. Systematic and Applied Microbiology 1994, 17, 625-635. 


\section{Combined Castor Marker and Isotope Profile for Ricin Forensics: Final Report}

Page 57 of 57

(20) Ehleringer, J. R., Kreuzer-Martin, H.W., West, J.B., Lowe, T.M., Barnette, J.E., and Hoffman, J. ; FBI report BAA-0034104: Salt Lake City UT, 2006.

(21) West, J. B., Kreuzer-Martin Helen W, Ehleringer, James R. In Isoscapes: Understanding movement, pattern, and process on Earth through isotope mapping; West, J. B., Bowen, G.J. Dawson, T.E. Tu, K.P., Ed.; Springer Science + Business Media B.V, 2010, pp 168-178.

(22) A, F.; L, M. S.; J, G., Eds. Preparation of alditol acetates and their analysis by gas chromatography and mass spectrometry. ; CRC Press: FL, 1989.

(23) Wunschel, D. S.; Colburn, H. A.; Fox, A.; Fox, K. F.; Harley, W. M.; Wahl, J. H.; Wahl, K. L. Journal of Microbiological Methods 2008, 74, 57-63.

(24) Adams, M. A.; Chen, Z. L.; Landman, P.; Colmer, T. D. Analytical Biochemistry 1999, 266, 7784.

(25) Rojas-Escudero, E.; Alarcon-Jimenez, A. L.; Elizalde-Galvan, P.; Rojo-Callejas, F. Journal of Chromatography A 2004, 1027, 117-120.

(26) Company, P. C. 1995, 0322, 1-7.

(27) Pierce Product Information 1995, 0322, 1-7. 